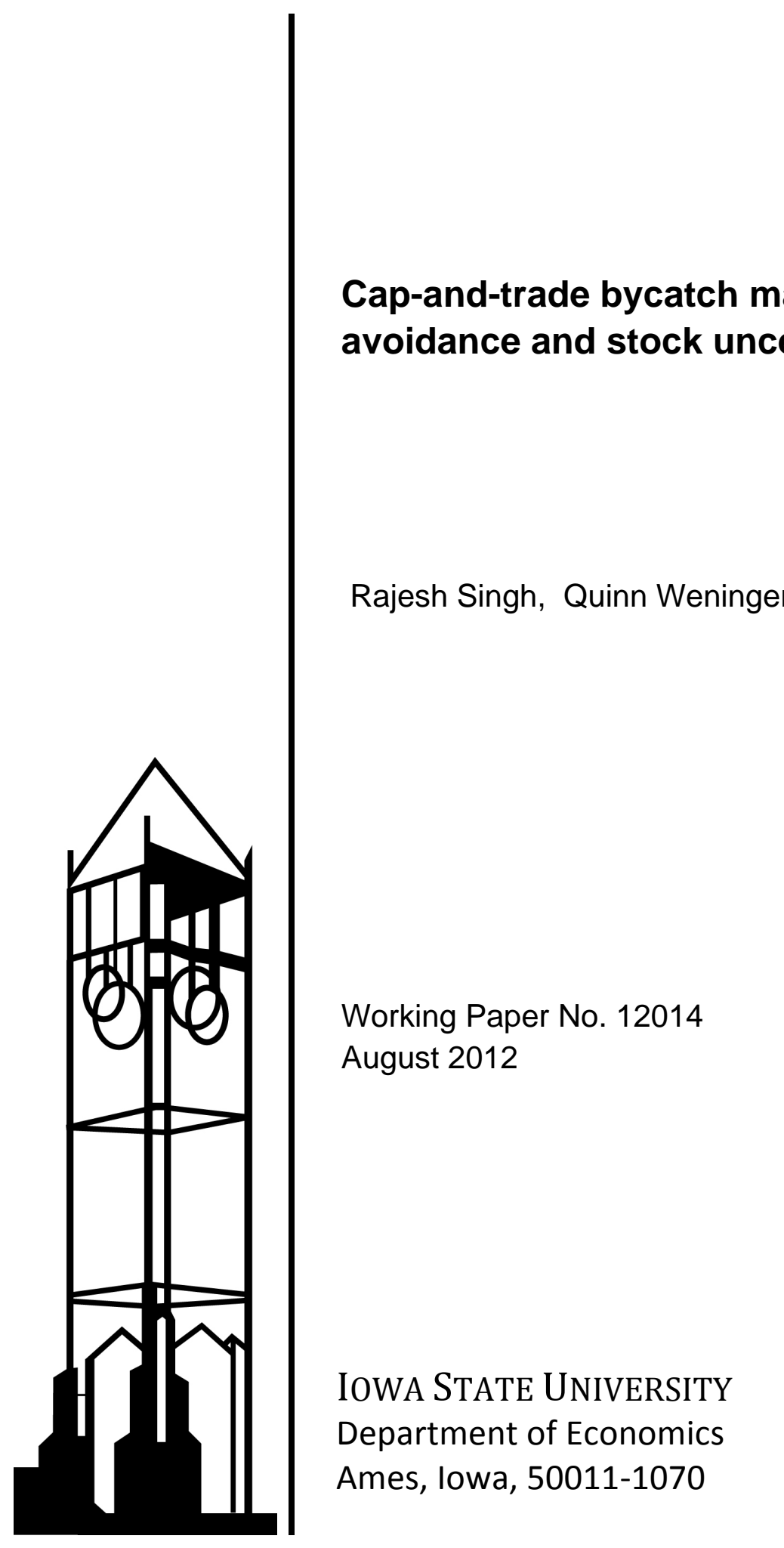

lowa State University does not discriminate on the basis of race, color, age, religion, national origin, sexual orientation, gender identity, genetic information, sex, marital status, disability, or status as a U.S. veteran. Inquiries can be directed to the Director of Equal Opportunity and Compliance, 3280 Beardshear Hall, (515) 294-7612. 


\title{
Cap-and-trade bycatch management with costly avoidance and stock uncertainty
}

\author{
Rajesh Singh \\ Iowa State University
}

\author{
Quinn Weninger* \\ Iowa State University
}

Revised: May 29, 2014

\begin{abstract}
Regulations to reduce bycatch of non-marketed marine species often impose gear restrictions, reductions in harvest of the target species, and/or spatial and temporal closures of the fishing ground. These regulations can exact significant social costs in commercial fisheries. We evaluate performance of a cap-and-trade bycatch management policy. Harvest of a target fish species, costly avoidance of the bycatch species, and harvesting efficiency is examined in a stochastic production environment with and without at-sea observability of bycatch, and with and without trade in harvest quotas and bycatch caps. Our results suggest that a precise implementation of a socially optimal management plan is possible only if bycatch is observable and trade in fish quotas and bycatch cap is frictionless. Conditions exist in which quota/permit trading raises bycatch relative to a no trade environment. The results offer useful guidance for designing cap-and-trade bycatch management programs.
\end{abstract}

JEL Classification: Q2

Keywords: Cap-and-trade bycatch management, costly bycatch avoidance, observability, quota trading.

\footnotetext{
*Correspondence: Quinn Weninger, Department of Economics, Iowa State University, Ames IA 50011 - 1040 , USA; Phone: 515-294-8976; E-mail: weninger@iastate.edu
} 


\section{Introduction}

National standard 9 of the Magnusun-Stevens Fisheries Management and Conservation Act requires that U.S. Fisheries Management Plans minimize, to the extent practicable, bycatch and bycatch mortality. Examination of U.S. fisheries suggest, however, that significant bycatch problems remain. A recent National Bycatch Report (NMFS, 2011) estimates that 1,887 marine mammals, 11,772 endangered sea turtles and 7,769 sea birds were intercepted by fishing gear in 2005, the base year of the study. Unintended bycatch and discard of non-target fish species is estimated at 1.22 billion pounds, or $17 \%$ of the total 2005 U.S. catch. An approach often used by resource managers to reduce bycatch of non-marketed but socially valuable marine species is to curtail fishing or regulate fishing practices. Alternatives that allow the benefits from commercial and recreational fishing to continue, while controlling unintended bycatch, are clearly preferred.

This paper studies the implications of controlling non-marketed bycatch with a system of tradeable bycatch permits. Under such a cap-and-trade bycatch regulation, the fishery manager issues a fixed number of permits each of which grants its owner the right to intercept a unit of the bycatch stock. Permit prices provide incentives for fishermen to avoid bycatch. Providing incentives to avoid bycatch offers an alternative to command-and-control regulations which seek to reduce bycatch directly through costly spatial, temporal and depth fishing closures, reductions in fishing effort, lowering of target stock harvest, and/or gear restrictions.

Our model features two key elements of the bycatch problem. First, fishermen employ a technology that yields conditionally uncertain harvest of the target and bycatch species. Randomness arises from unobserved absolute and relative abundance of the target and bycatch stocks in the sea. Second, we assume fishermen can exert partial control over the mix of target and bycatch species encountered by their gear; bycatch avoidance is a choice variable in our model. A weak output disposable harvest technology is proposed under which reductions in bycatch involve reductions in the harvest of the saleable target species. The model thus allows us to investigate the endogenous bycatch-to-target harvesting decisions that arise in equilibrium under a quota-based regulation. While these features have been introduced separately in earlier literature, combining both into a single framework builds new insights for the design of quota-based bycatch management programs.

We derive and compare equilibrium harvests, landings, discards of the target and bycatch species, permit prices and input costs under varying program designs including a scenario where at-sea harvesting operations are fully observed by the fishery manager, and another where at-sea actions are unobserved. The latter case describes most fisheries in the U.S. and worldwide due to the high cost of placing observers on fishing vessels. While observability is a must for implementing bycatch cap-and-trade, our analysis of the unobservable bycatch case provides a baseline for comparison with non-quota-based management instruments such as effort reductions, area or seasonal closures, and gear modifications, which can be implementable without observers.

We also examine the implications of permit trading restrictions, which may arise due to transactions costs, e.g. thin bycatch cap markets, or regulatory prohibition. We show that management performance generally deteriorates in the absence of trade. Without permit trade, the cost of landing a given quantity of the target stock is higher, although bycatch may fall below the target set by the manager. The intuition for the lower bycatch result is the following. In the absence of post-harvest quota trade, any harvest overage of the target fish stock must be discarded, while harvest uncertainty causes some fishermen to land less than their quota. In the aggregate, there is 
a larger input employment to land the same amount of fish. Costs rise and profitability declines. The larger input allocation provides added maneuvering slack to further reduce bycatch. A reduction in bycatch in the no trade case, by no means, should be interpreted as an argument against trade. Trade allows aggregate target quota and bycatch caps to be met. Therefore, if these targets are optimally chosen, the equilibrium outcome under trade in quotas and bycatch permits is more efficient.

As one would expect, our model also predicts that an observer program that can monitor and enforce bycatch caps at sea, commands fishermen to employ inputs capable of harvesting their target-stock quota while meeting bycatch limits. Placing observers on boats has its own costs. As a result, while bycatch can be brought down to the desired level, harvesting costs will rise. An observer program to cap bycatch at a socially optimal level has to thus balance bycatch reduction benefits with its increased monitoring costs.

Cap-and-trade management is an alternative to non-quota-based regulations that attempt to reduce bycatch through: (i) reductions in fishing effort and/or target stock harvest; (ii) closure policies which limit access to the target stock at chosen times, depths, or in regions of the fishing ground where the bycatch stock is believed to be concentrated; and (iii) fishing gear modification. These regulations are popular in fisheries, possibly due to relatively low administrative costs of implementation, for example, by avoiding costly onboard observers. Empirical evidence of the effects and costs of non-quota-based regulations in the Gulf of Mexico longline reef fish fishery, which we provide as motivation for our study, suggests significant social costs in terms of forgone harvest and fishing profits. While data limitations do not permit an exhaustive cost-benefit analysis of competing bycatch management approaches, the evidence we provide suggests that quota-based bycatch management warrants serious consideration by managers.

The remainder of the paper is organized as follows. The next section briefly reviews the marketbased bycatch management literature. Section 2 presents an abbreviated case study of the Gulf of Mexico longline reef fish fishery to highlight the costs of non-quota-based regulations and motivate need for alternative (quota-based) bycatch management approaches. Section 3 introduces our model. Results are derived in section 4. Conclusions and closing comments appear in section 5. An appendix to the paper, which is available from the authors on request, contains proofs of key derivations, empirical examples, analysis under alternate model assumptions, and ancillary empirical results.

\section{$1.1 \quad$ Related literature}

Efforts to reduce bycatch and discards of fish, birds and sea mammals have spawned a large literature in the fisheries sciences and economics. ${ }^{1}$ Bycatch management policy has generally followed two somewhat independent paths. One focuses on modifying fishing gear to improve gear selectivity, i.e., designing gear to lower the quantity of bycatch intercepted per unit of harvested target stock. Examples include turtle excluder devices on shrimp trawl nets, and circle hooks (as opposed to traditional J-hooks) which tend to snag fewer sea turtles and cause less damage when turtles are

\footnotetext{
${ }^{1}$ We do not attempt a full review of this literature here. In addition to Gilman et al. (2006), see Lewison and Crowder (2004), Pascoe et al. (2010) and references therein. Economists (e.g., Arnason (1994), Boyce (1996), Turner $(1995,1997)$ and more recently Singh and Weninger (2009)) have examined economic trade-offs implicit in multiple-species quota management programs and the associated bycatch problem. See Hutton et al., (2010) for a review.
} 
hooked. Gilman et. al. (2006) summarizes the state of knowledge regarding sea turtle avoidance technologies. A second path, one followed in this paper, seeks to design regulations that provide fishermen with incentives to undertake costly bycatch avoidance.

Fishermen make many production decisions that can influence the mix of species intercepted by their gear, e.g., choice of fishing time, fishing depth and location, gear and bait combinations, net mesh sizes, duration of soak times for baited hooks, use of sonar equipment which can increase awareness of species vulnerable to capture (see Branch and Hilborn (2008) for empirical evidence). Bycatch avoidance is privately costly and therefore providing incentives to incur avoidance costs can be an effective management tool (Bisack and Sutinen (2006); Segerson (2011); Muhkerjee and Segerson (2011); Pascoe et. al, (2010)). Economic incentives for bycatch avoidance in cap-andtrade management programs, as we show, depend crucially on fish quota and bycatch permit prices. A key novelty of our approach is that we investigate an explicit harvest-bycatch technology that, within an equilibrium framework, allows us to study the properties of endogenously determined fish quota and harvest bycatch permit prices, and their role in shaping fishermen's harvesting and bycatch avoidance behavior. As a result, our framework enables a quantitative evaluation of the ecological and economic outcomes expected under a target/bycacth species quota/cap regulation.

Our paper most closely relates recent work by Segerson (2011) and Holland (2010). ${ }^{2}$ Segerson (2011) presents a model of costly bycatch avoidance to study social efficiency under various bycatch management policies, including taxes on the harvest of target and bycatch stocks, limits on allocated effort, and penalties or fines levied when a bycatch limit is exceeded. In her model, the harvest of the target stock is deterministic, and bycatch encounters are random. Segerson (2011) finds that taxes, fines and caps placed on the bycatch stock at the individual fisherman level can lead to socially efficient bycatch avoidance, whereas similar measures imposed on target stock generally do not achieve efficient outcomes. To induce efficient bycatch avoidance, Segerson (2011) suggests an industry-wide bycatch quota with a proportional penalty/reward that is paid by/to all members when the group limit exceeds/falls below the management target. Segerson (2011) does not evaluate a cap-and-trade bycatch policy at the industry level, and does not consider the implications of unobservable bycatch. Our work contributes to the bycatch literature in these two respects.

Holland (2010) studies the impacts of individual bycatch quotas in a model of fishing uncertainty, with a focus on the role of risk aversion in bycatch voidance behaviors. Holland (2010) simulates bycatch, quota prices and fishing profit distributions numerically under competing assumptions for risk preferences, randomness in production, and quota pooling arrangements adopted by fishermen. Holland (2010) argues that quota pooling arrangements used in the British Columbia groundfish trawl fishery reduce risk exposure and inefficiencies that would otherwise arise due to thin quota markets. Holland (2010) assumes for simplicity that bycatch encounters are purely random, acknowledging however that in reality fishermen affect bycatch by changing when, where and how they fish, and the gear they use (Holland, 2010, p. 123). ${ }^{3}$ Our model extends the work of Holland (2010) by incorporating endogenous bycatch avoidance in a quota/permit market equilibrium framework.

\footnotetext{
${ }^{2}$ Earlier work by Boyce (1996) develops a stylized model of the fisheries bycatch problem to address issues related to the allocation of a fixed bycatch allowance across multiple users, and conditions under which individual transferable bycatch quotas can replicate socially optimal outcomes. In the Boyce (1996) model, the quantity of bycatch intercepted by fishermen is given exogenously as an fixed (perhaps increasing) proportions of harvest; endogenous bycatch avoidance is not considered.

${ }^{3} \mathrm{~A}$ few studies have attempted to measure the cost of sea turtle bycatch management regulations. Curtis and Hicks (2000) estimate the cost of closing portions of Hawaii's pelagic longline fishing ground. Chakravorty and Nemoto (2000), Huang and Leung (2007), and Pradhan and Leung (2005) apply various empirical techniques to estimate the cost of reducing sea turtle bycatch in the same fishery.
} 
Quota-based bycatch policies have received increasing attention from managers and researchers (Fisheries Leadership and Sustainability Forum (2009); Abbott and Wilen (2009); Holland (2010)) and warrant further analysis. Our contribution to the bycatch literature is manifold. We focus on the role of markets in implementing aggregate target species and bycatch limits in a setting of production uncertainty and endogenous bycatch avoidance. Importantly, we study equilibrium outcomes including factor input allocation, harvest, avoidance efforts of fishermen, and bycatch outcomes under target/bycatch quota-management. Finally, since unobservability is a fact of life in most fisheries and quota/permit tradeability is often limited by market thinness or through regulatory restriction we contrast equilibrium outcomes under these two phenomenon. Last, our comparisons with non-quota-based regulations offers crucial insight for regulators and industry faced, under the Magnusun-Stevens Fisheries Management and Conservation Act, with the task of reducing bycatch.

The rest of the paper is organized as follows. For concreteness we focus our analysis on the bycatch of mega-fauna, and particularly sea turtles in longline fisheries. The next section reviews nonquota based sea-turtle bycatch regulations in the U.S. Gulf of Mexico commercial reef fish fishery and, to further motivate consideration of a quota-based bycatch management approach, provides empirical evidence of the cost of these regulations. Section 3 introduces our model of a costly and stochastic technology in a target- and bycatch-stock fishery. Section 4 analyzes equilibrium landings, bycatch, and quota/cap prices in a quota-based management program, under trade and no trade environments and with and without at-sea observability. Proofs and additional derivations are presented in an appendix. Section 8 analyzes non-quota-based programs. Section 5 summarizes our main findings and discusses directions for future research.

\section{Bycatch management in the GOM commercial reef fish fishery}

The Gulf of Mexico commercial reef fish fishery is a complex of mid-column and bottom-dwelling species consisting of snappers, groupers, tilefish, amberjacks, triggerfishes, grunts, porgies, and a host of others. Fishermen also harvest coastal pelagic species such as mackerel, dolphin, sharks and tuna. Total landings in the fishery have ranged between 13.053-16.645 million pounds annually, between $2005-09$. Annual dockside revenue has varied between $\$ 36.884-\$ 43.227$ million during the same period. ${ }^{4}$

Two main gear types are employed in the commercial reef fish fishery. Vertical line gear is the most common followed by longline gear (fish traps, nets and trolling gear are also used). Longline fishing involves deploying a long cable with as many as 2,000 smaller ganion lines, each containing a baited hook, to the desired fishing depth. The gear is soaked from anywhere between 2-10 hours. It is then retrieved with a hydraulic winch. Captured reef fish are removed from the hooks, eviscerated, and placed on ice for transport back to port. ${ }^{5}$

Loggerhead turtles (Caretta caretta) are the main turtle species intercepted by longline fishermen,

\footnotetext{
${ }^{4}$ In 2010, commercial fishing in the Gulf of Mexico was impacted by the Deepwater Horizon oil spill disaster, which led to spatial closures and significant disruptions to commercial fishing activity. We do not report data for 2010 as it likely does not reflect normal fishing activity. Our data do not include a complete record on 2011 fishing activity. All dollar values are reported in 2011 dollars.

${ }^{5}$ Fishing with vertical line gear involves lowering multiple baited hooks on vertical main lines off the side of the vessel. When reef fish are captured, the line is retrieved, fish are removed from hooks, eviscerated, and placed on ice for transport back to port. Turtle encounters are not considered a problem with vertical line gear.
} 
although gear interactions with Kemp's Ridleys (Lepidochelys kempii) and leatherbacks turtles (Dermochelys coriacea) may also occur. Turtles can become entangled in the longline ganion or hooked as they pursue the same feed used as reef fish bait. Entangled turtles may drown or be seriously injured and die. Turtle encounters with vertical line gear are virtually non-existent due to the very short soak time; once a boat is on fish, baited hooks can be lowered and retrieved quickly with little opportunity to attract and entangle turtles.

An on-board observer study conducted by the National Marine Fisheries Service from July 20062008 recorded turtle encounters on $17.6 \%$ of longline trips, and on $1.9 \%$ of sampled sets (see NMFS, 2009). Extrapolation to total longline effort allocated during the study period predicts that 861 sea-turtle encounters (95\% confidence interval at 384-1,934) during the 20 month period. The estimated turtle take exceeds permissible levels under the U.S. endangered species Act, requiring the NMFS to take regulatory action to reduce the number of sea turtle encounters. ${ }^{6}$

In May 2008, the Gulf of Mexico Fisheries Management Council enacted three emergency measures to reduce sea-turtle bycatch. Longline fishermen were prohibited from setting gear shoreward of a line approximating the 35 fathom contour eastward of the 85 degree, 30 minute longitude, across most of the Florida Gulf coast. Second, longline fishermen were permitted to carry no more that 1,000 hooks onboard their vessel, of which 750 could be rigged for fishing. Hook limits are intended to limit the length of the longline, which effectively reduces soak time, a factor thought to be positively related to sea turtle encounters and mortality. Lastly, managers limited the number of vessels that were permitted to use longline gear. Amendment 31 was passed in May 26, 2010, making made the emergency rules permanent.

Amendment 31 does not include provisions for on-board observers. The location of a fishing vessel is tracked electronically with satellite-based global positioning technology which enforces depth restrictions at relatively low cost. Likewise, the number of hooks on board and vessel permits can be monitored at port thus avoiding the need and expense of onboard observers. Examination of logbook records collected by the National Marine Fisheries Service suggests that Amendment 31 regulations have affected fishing practices and raised harvesting costs in the Gulf reef fish fishery.

\subsubsection{Implications and cost of Amendment 31 regulations}

\begin{tabular}{cccccccc}
\hline \hline \multicolumn{7}{c}{ Table 1: Longline Gear Effort, Landings and Revenue, 2006-10 } \\
\hline \multicolumn{7}{c}{ Effort } & \multicolumn{5}{c}{ Landings ('000 lbs.) } & \multicolumn{2}{c}{ Revenue ('000 \$) } \\
Year & Trips & Vessels & DAS & All Spec. & Red Grp. & All Spec. & Red Grp. \\
2005 & 2,028 & 170 & 12,908 & 7,508 & 3,085 & $\$ 16,303$ & $\$ 8,974$ \\
2006 & 2,128 & 145 & 14,343 & 7,482 & 2,991 & 16,268 & 9,461 \\
2007 & 1,362 & 134 & 12,068 & 4,968 & 1,938 & 13,835 & 6,456 \\
2008 & 1,385 & 124 & 12,405 & 5,338 & 2,772 & 15,172 & 8,473 \\
2009 & 793 & 105 & 7,690 & 3,214 & 1,084 & 8,713 & 3,242 \\
\hline \hline
\end{tabular}

Table 1 reports annual fishing effort, landings, and revenue for the Gulf longline fleet during the

\footnotetext{
${ }^{6}$ Sea turtles are listed as endangered under the Endangered Species ACT (ESA). By law, the National Marine Fisheries Service must adopt fisheries regulations that are deemed not a threat to the existence of sea turtles. Encounters during legal commercial fishing activities at or below levels that satisfy this requirement are permissible under ESA law.
} 
2006-09 fishing seasons. We report landings and revenues for all reef fish species combined, and for the longline fleet's main target species, red grouper. ${ }^{7}$ Recall that longline bycatch management regulations began in May 2008. The first full year of the regulation is 2009.

Table 1 reports that 19 fewer vessels fished with longline gear in 2009 than in 2008. This decline is more pronounced if we consider dedicated longline gear boats. If we measure participants as vessels that used longline gear on the majority of their annual trips, the longline fleet size dropped from an average of 117 vessels in 2005-08, to 73 in 2009. Total longline gear trips declined from 1,385 in 2008 to 793 trips in 2009, a $42 \%$ drop. Landings and revenues also declined sharply in 2009. The decline is most pronounced for red grouper where landings fell $39 \%$ and revenues fell $38 \%$ between the 2008 and 2009 fishing seasons.

Logbook data provide evidence that reef fish fishermen switched gear types in response to Amendment 31 regulations. The number of vertical line fishing trips increased by 749 in 2009, a $10 \%$ increase over 2008 trips. Landings by vertical line gear (all species) increased by 17\%, and vertical line landings of red grouper increased by $21 \%$ between 2008 and 2009. Total landings for both gear types fell $4.4 \%$ to 13.306 million pounds and total revenue declined by $\$ 4.53$ million, or $11.1 \%$, in 2009.

\begin{tabular}{ccccccccc}
\hline \hline \multicolumn{1}{c}{ Table 2: Harvest Costs per landed pound (all reef fish species) } \\
\hline \multicolumn{4}{c}{ Longline Gear } & \multicolumn{5}{c}{ Vertical Line Gear } \\
& Trips & Ave. & Std. & Med. & Trips & Ave. & Std. & Med. \\
2005 & 1,495 & 1.53 & 0.93 & 1.23 & 9,039 & 2.53 & 1.52 & 2.04 \\
2006 & 1,409 & 1.74 & 0.97 & 1.47 & 8,570 & 2.63 & 1.55 & 2.14 \\
2007 & 1,175 & 1.83 & 0.97 & 1.50 & 6,029 & 2.68 & 1.60 & 2.16 \\
2008 & 1,209 & 1.66 & 1.02 & 1.33 & 6,086 & 2.51 & 1.51 & 2.03 \\
2009 & 689 & 1.70 & 1.14 & 1.36 & 6,639 & 2.44 & 1.44 & 2.01 \\
\hline \hline
\end{tabular}

Table 2 reports summary statistics for fishing costs. Not all reef fishing trips record cost information, which is why the number of trip observations is smaller than in Table $1 .^{8}$

For longline gear, sample average cost per landed pound varies between $\$ 1.53-\$ 1.83$ in 2005-09. A small increase in the average cost per pound is indicated in 2009 when bycatch regulations took hold. The average cost per landed pound on vertical line gear trips is higher with a range of $\$ 2.44-\$ 2.68$. Averaging across years, vertical line gear trips incur roughly $\$ 0.87$ higher cost per landed pound than longline gear trips. If we compare median values, vertical line gear costs are, on average, $\$ 0.70$ more per landed pound.

Information on revenues and costs reported in Table 2 suggest that regulations that reduce longline gear fishing in the Gulf reef fish fishery are indeed costly. Reef fish fishermen are able to switch gear types which offsets the losses from reductions in longline fishing. However, cost comparisons across gear types suggest harvesting with vertical line is more costly. A few simple calculations demonstrate.

\footnotetext{
${ }^{7}$ The majority of longline fishing takes place off the western Florida coast where red grouper is a prominent species.

${ }^{8}$ Trip costs include (1) expenses for fuel, bait, ice, and other miscellaneous expenses (from logbook data), (2) payments to captain and crew labor, which we calculate as the estimated crew share times the trip revenue, and (3) fixed operating expenses. Details for crew share calculations and fixed operating expenses are reported in Appendix 7.8 .
} 
Total landed pounds by both gear types during 2005-2010 has remained fairly constant at roughly 13.6 million pounds per year. The average share of landings on longline vessels between 2006-08 was 0.415 . The longline gear landings share dropped to 0.242 in 2009. Assume the longline share of reef fish landings would have remained at 0.415 in 2009 had longline effort restrictions not been imposed. Using the 2009 sample average cost per landed pound from Table 2, the fleet aggregate costs would have been $\$ 1.70$ million less. It should be noted that the data generating process underlying Table 2 included depth restrictions and trip hook limits. The $\$ 1.70$ million cost saving can therefore be viewed as a lower bound.

\section{The model}

The harvest environment we have in mind is a single fishing season in which the stock size of the target and bycatch species are given. Due to random fluctuation in the marine environment, e.g., changing weather, water temperatures, currents, and the distribution of feed, the relative mix of the target and bycatch species varies.

We assume the number of fishermen is pre-determined and large. To simplify our analysis, we assume a continuum of ex ante identical fishermen with a unit mass operate in the fishery. ${ }^{9}$ The continuum assumption allows us to apply the law of large numbers, and scaling by unit mass lets expected outcomes equal actual aggregate outcomes.

There are two stocks: a target species stock and a bycatch stock. For concreteness the target species will be fish and the bycatch will be sea-turtles. Fish have consumptive use value and fetch a positive unit price at the dock. Sea turtles have non-use value only. Harvesting operations are conducted within a single production period. Individual fishing quotas grant their owners a right to harvest a specified quantity of the target species during a fixed calendar period. Bycatch permits legalize turtle encounters. In our model, the production period and fishing season coincide. ${ }^{10}$

Measures can be taken to avoid bycatch but these measures utilize resources. For example, shorter soak times and fishing at night, which has been shown to reduce sea turtle encounters with longline fishing likely requires additional labor. Sea-turtle interceptions with longline fishing gear is affected by the type of hooks used, the type of bait, the depth and location of fishing, the length of time baited hooks are soaked in the water, day versus night fishing (Gilman et al., 2006). We model the cost of bycatch avoidance as reduced harvest and landings of fish for a given input allocation. ${ }^{11}$ To be precise, we assume fishermen choose a variable $c$ which determines the point along a targetbycatch transformation frontier at which production takes place. In particular, reducing bycatch

\footnotetext{
${ }^{9}$ The assumption of ex-ante homogenous fishermen is not necessary for the key results derived in this paper. Allowing for heterogenous fishermen will unnecessarily complicate the model and add few new insights. In Appendix 7.4 we analyze the effect of area closures with heterogenous fishermen, where managers as well as fishermen have perfect location-specific knowledge of the stock mix. We show that our results are qualitatively invariant to whether agents are ex-ante or ex-post heterogenous.

${ }^{10}$ An alternate interpretation of our model is that the fishing season is divided into a finite number of production periods. The analysis that follows would then apply to the final period in which the target species quota and bycatch permits bind, and aggregate quotas/permits denote remaining, unfished quota/bycatch permits. Backward induction could then be used to analyze avoidance behavior, quota prices, etc., in periods leading up to the final period. A formal analysis of the multiple-production-period case is not attempted here.

${ }^{11}$ Segerson (2011) presents a model that is dual to ours; fishermen choose a costly action that lowers the probability of intercepting sea turtles. In her model, increased avoidance raises costs and reduces the quantity of fish that is harvested per gear set.
} 
by a proportion $c$ from its natural baseline level reduces fish harvest by the proportion $a(c)$. The avoidance-augmented technology is expressed as

$$
\left\{h_{f}, h_{t}\right\}=\left\{z_{f}(1-a(c)) \phi^{1-\beta}, z_{t}(1-c)(1-\phi)^{1-\beta}\right\} n^{\beta}
$$

We assume an increasing and strictly convex product transformation between the target and bycatch species. In our framework, the marginal foregone fish harvest that results from a marginal reduction in bycatch increases with additional avoidance. Formally, we assume $a(0)=0 ; a(1) \in(0,1) ; a^{\prime}$, $a^{\prime \prime} \geq 0$ with strict inequality for $c>0$; and $a^{\prime}(0)=0, a^{\prime}(1)=\infty$. Thus, $a(c)<c$ for all $c$. These assumptions ensure the profit maximization problem is strictly concave in $c$. We allow $c \in[0,1]$. Thus, a sufficiently high avoidance effort eliminates bycatch completely, while still yielding a positive quantity of harvest. ${ }^{12}$

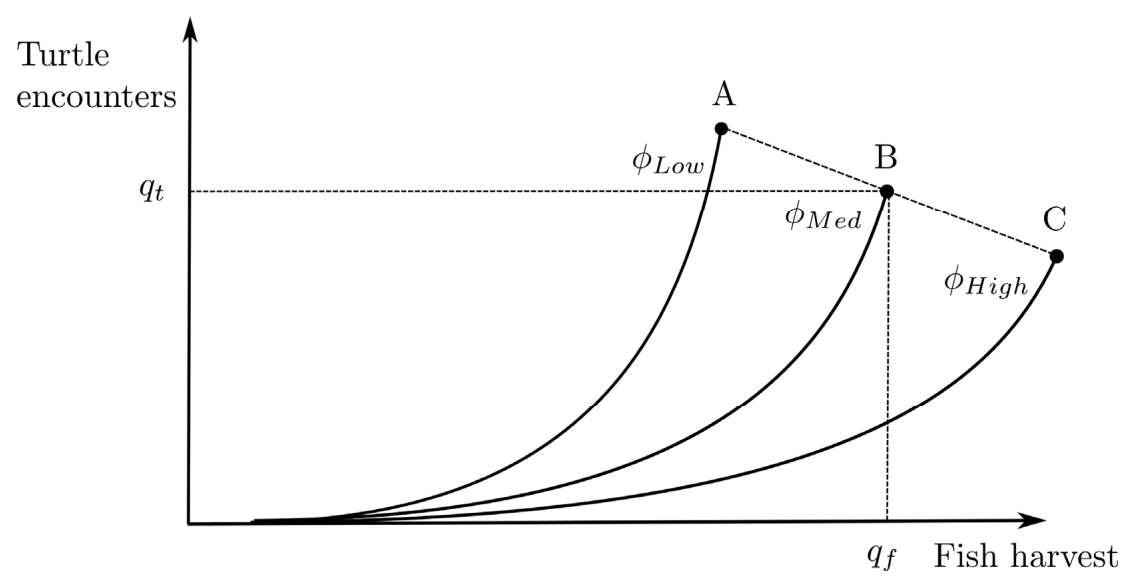

Figure 1: Relative stock abundance and harvesting technology. Figure depicts the avoidance augmented technology under the assumption $a(c)=\frac{1-\sqrt{1-c^{2}}}{2} ; \phi$ takes a low $\left(\phi_{L O W}\right)$, medium $\left(\left(\phi_{M E D}\right)\right)$ and high $\left(\phi_{H I G H}\right)$ value.

Figure 1 depicts the avoidance augmented technology. Maximum harvests of the target and bycatch species for a common $n$ is denoted $\mathrm{A}, \mathrm{B}$, and $\mathrm{C}$ in the figure for $\phi$ at a low, medium and high values. All three harvest outcomes correspond to the case where no effort/input is spent on bycatch avoidance, i.e., $c=0$. If the fisherman chooses maximum avoidance, i.e., $c=1$, bycatch is eliminated but harvest of the target species is reduced to a fraction of its maximum value.

Harvesting uncertainty is introduced as follows. We assume that when input $n$ is chosen, a fisherman knows only the distribution of relative stock abundance, $\phi$. Once at sea, actual realization of $\phi$

\footnotetext{
${ }^{12}$ The technology could be parameterized as null-joint in outputs where zero bycatch is feasible only with zero harvest of the target species.
} 
occurs, as fishing reveals stock conditions under the boat so to speak. Fishermen then choose avoidance $c$ to intercept their preferred quantities of fish and bycatch.

Our assumptions for uncertainty results in a choice problem that is solved in two stages. In the first stage, input bundle $n$ is chosen based on the known distribution of $\phi$. We call this the planning stage. The second operations stage begins once $\phi$ and the harvest possibilities are realized. It is clear from (1) that a higher $\phi$ rotates the fish-bycatch frontier clockwise (see Figure 1). In what follows, we let $G(\phi)$ and $g(\phi)$ denote the CDF and PDF of $\phi$ with a support $\left[\phi_{\min }, \phi_{\max }\right]$, with $0 \leq \phi_{\min }<\phi_{\max } \leq 1$, and $x^{e} \equiv E\{x\} \equiv \int x g(\phi) d \phi$ denotes the expected value of a variable $x$. We use $H(n, \phi)=\left\{h_{f}(n, \phi), h_{t}(n, \phi)\right\}$ to denote the harvest-bycatch possibilities frontier (HBPF). For a given $H(n, \phi)$, input price, dockside fish price, and regulations limiting harvest and bycatch, fishermen choose $n$ in the planning stage to maximize expected profits (denoted by $\pi^{e}$ ) and $c$ in the operations stage to obtain their desired harvest/bycatch mix on the HBPF.

A few words about the model set up are warranted. Uncertainty in relative abundance generates a stock-mix realization in which some lucky fishermen realize a high target to bycatch stock mix; unlucky fishermen realize the opposite. This generates a natural environment for trade in fish quotas and bycatch caps: the lucky ones will wish to buy more fish quotas while the unlucky will seek more of turtle permits. Having a single parameter $\phi$ as opposed to two separate stock uncertainty parameters simplifies the analysis. Uncertainty is idiosyncratic in our model. Uncertainty in the aggregate stock levels is important for setting fishery-wide targets and quantitative evaluation of alternative regulatory regimes, however, here our focus is on bycatch avoidance behavior under quota- and non-quota based regulations. Aggregate uncertainty in quota managed fisheries is examined in Singh and Weninger (2012).

Alternate assumptions could be made regarding the timing of input choices and realization of uncertainty. In an Appendix 7.3) we assume stock conditions $\phi$ are revealed before the input bundle is chosen. This case is equivalent to assuming that inputs are perfectly reversible. Our model assumes the planning stage input choice is irreversible. As example, a fisherman organizes crew, bait fuel, etc. based on expectation of stock conditions. Trip capital, labor, fuel and bait has been committed and the challenge is to organize the input bundle to optimize trip revenues. While the full irreversibility assumption may be somewhat extreme, it captures the essence of input choice under uncertain production. Nonetheless, we take care throughout our analysis to indicate where results can change when the irreversibility assumption is relaxed.

A second scenario models the production decision as a one-shot event in which $n$ and $c$ are both chosen prior to the random harvest/bycatch realization (e.g, Segerson, 2007). Our model features endogenous bycatch avoidance combined with harvest uncertainty. A one-shot model would require that we take a stand on the proportion of bycatch caused by pure randomness versus the proportion caused by avoidance actions and the results would depend on this choice (see Abbott, 2007). Adding pure randomness to catch outcomes would require specification of penalties in the event of quota overages. This would introduce behavioral incentives different from those that arise from buying and selling quota in a decentralized quota- and bycatch-cap fishery. It is the latter incentives that is of interest in this paper. For this reason, there is no unintended bycatch in the operations stage of our model. In effect, we assume that all bycatch can be avoided at a sufficiently high cost. This assumption may be reasonable for longline gear where fishermen have several options to avoid turtles (Gilman, et al. 2006).

Finally, we assume the fishery manager has accounted for the social costs/benefits when setting 
the target fish stock quota and quantity of turtle bycatch permits. In fact, these choices depend on harvesting costs which we show vary with the form of the regulation. Determination of the jointly socially optimal fish quota and turtle bycatch cap is reserved for future work.

\section{Cap-and-trade bycatch management}

We now consider the implications of our costly bycatch avoidance model in a fishery that is managed with individual quotas for the target fish stock, and permits for turtle bycatch, denoted in the model as $q_{f}$ and $q_{t}$, respectively. Corresponding quota/cap prices are denoted by $r_{f}$ and $r_{t}$. We begin with a case where at-sea fishing activity is unobserved by the manager. This scenario approximates a regulation with no effective controls on harvest of the bycatch stock, and thus no incentive to undertake costly bycatch avoidance. Analysis of the case where at-sea fishing activity is observable is discussed later. In each case, we contrast scenarios where quota is and is not tradeable.

\subsection{Quota-based management without at-sea observability}

Assume dockside landings are monitored but at-sea fishing operations are unobserved by the regulator. We assume the fishermen's objective is to maximize private fishing profits. Fishermen harvest no more than their quotas, even if it is feasible to do so. Furthermore, while sea-turtle bycatch is socially undesirable, and fishermen will take necessary measures to avoid it, minimizing bycatch yet remains a secondary objective. ${ }^{13}$ Thus if in the operations stage the realized HBPF permits full utilization of quotas, we assume fishermen choose a $\left\{h_{f}, h_{t}\right\}$ pair that obtains the lowest turtle bycatch. For example, suppose a fisherman realizes the HBPF depicted in Figure 2 below. If his quota and bycatch cap is $\left\{q_{f}, q_{t}\right\}$, harvest will be at point $A$, and both fish quota and turtle bycatch

cap will be met. On the other hand, if his quota is $\left\{q_{f}^{\prime}, q_{t}\right\}$ at point $B$, he will harvest $q_{f}^{\prime}$ and ignore (and violate) his turtle bycatch cap by harvesting at point $C$ because the bycatch overage is unobservable.

\subsubsection{Fish harvest and bycatch under trade in quotas}

Suppose fish quotas are traded in fully functional quota markets. We focus on fish quotas that have a positive price, i.e., $r_{f}>0$. This requires that all the quota supplied, $q_{f}$, is bought and the quota binds in equilibrium. Since quotas can be traded both before and after the HBPF is realized, by invoking arbitrage we assume that the same price prevails in both sub-periods.

At the planning stage, a fisherman anticipates his operations stage choices, contingent on the realized random stock, to be rationally optimal. With this sequence in mind, we can solve for the equilibrium fish harvests and turtle bycatch by applying backward induction.

The operations stage Without at-sea observability of fishermen's actions, any cap on sea-turtle bycatch is meaningless. Effectively, the price of turtle by-catch is zero, and a fisherman's optimal

\footnotetext{
${ }^{13}$ Sea turtle bycatch management policies exist because set turtles have non-consumptive social value. Fishermens' non-consumptive values have been ignored to simplify our analysis.
} 


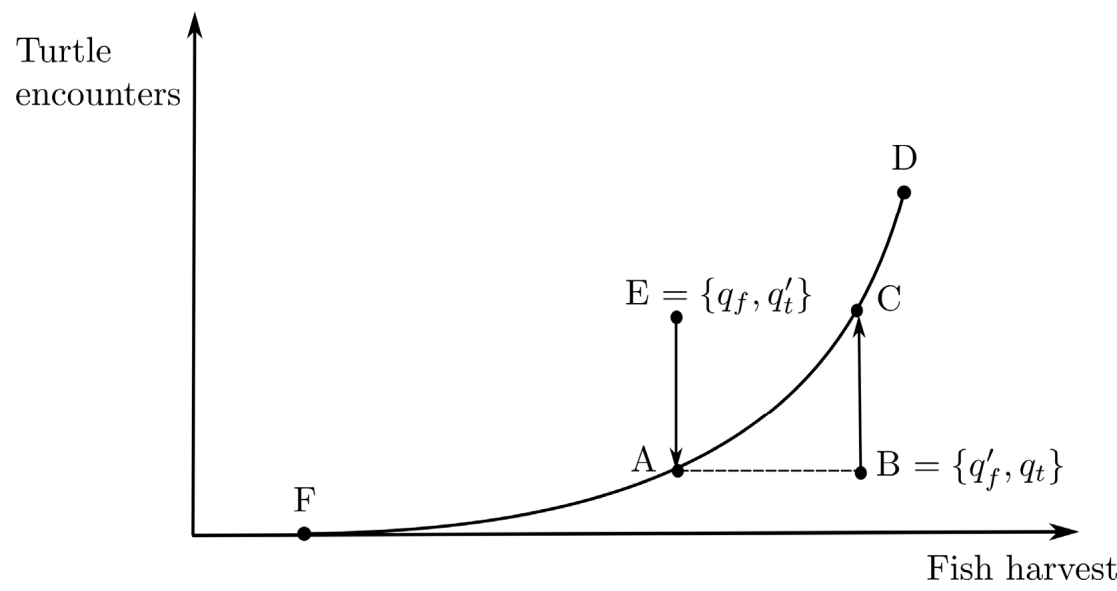

Figure 2: Harvest choices for different fish quotas and bycatch caps.

choice will be to maximize revenues from fish harvest. Let the dockside price of fish be $p_{f}$. As long as the quota price satisfies $r_{f}<p_{f}$, a fisherman will not incur any avoidance costs and choose $c=0$ to maximize fish harvest. ${ }^{14}$ This is shown as point $D$ in Figure 2 above.

Suppose fish quota bought by all ex-ante identical fisherman is $q_{f}$ as shown in Figure 1. Then a fisherman with a realization of $\phi_{M e d}$ simply harvests at point $B$ with $z_{f}\left(\phi_{M e d}\right)^{1-\beta} n^{\beta}=q_{f}$, and does not enter the quota market. The fisherman with $\phi_{\text {High }}$ on the other hand can harvest more than his quota, and as $r_{f}<p_{f}$, will buy additional quota from a fisherman with realization such as $\phi_{\text {Low }}$, e.g., at point $A$. The equilibrium quota price $r_{f}$, by arbitrage, equals its market price at the planning stage.

The planning stage At the planning stage, fishermen choose inputs $n$, keeping in mind their optimal operational responses to all possible realizations of $\phi$. They know their harvest will be a pair given by (1), i.e., the frontier points represented by $A-B-C$ in Figure 1. The problem then is to choose $n$ and $q_{f}$ to maximize expected profit:

$$
\pi^{e}=\left(p_{f}-r_{f}\right) E\left[\phi^{1-\beta}\right] \cdot z_{f} n^{\beta}-w n
$$

\footnotetext{
${ }^{14}$ With no aggregate uncertainty, $r_{f} \in\left(0, p_{f}\right)$ holds. Under aggregate uncertainty ex-ante and ex-post quota prices will be different. Also, if ex-post harvest turns out to be sufficiently high, there may be an excess demand for quotas driving $r_{f}=p_{f}$. In such cases, discard will also occur.
} 
where $w$ is the per unit price of the input and $E$ is the expectations operator. ${ }^{15}$ An interior choice of $n$ solves

$$
\beta\left(p_{f}-r_{f}\right) E\left[\phi^{1-\beta}\right] \cdot z_{f} n^{\beta-1}=w .
$$

Thus, inputs are employed to equate the value of their marginal product (LHS) with their marginal factor cost (RHS). In equilibrium, $r_{f}$ is determined from the above and the quota market clearing condition:

$$
E\left[\phi^{1-\beta}\right] \cdot z_{f} n^{\beta}=q_{f}
$$

Notice that the assumption of unit mass, ex-ante homogeneity, and i.i.d. realizations of $\phi$ across fishermen, equates the expected with the aggregate harvest (LHS). The first two assumptions also imply that the aggregate quota in the market equals that held by an individual. To economize on notation, this feature will be repeatedly exploited in the rest of the paper.

By combining (2) and (3), the quota price can be expressed as

$$
r_{f}=p_{f}\left(1-\frac{w n}{\beta p_{f} q_{f}}\right) .
$$

The quota price can be interpreted as per unit market earnings, net of its utilization costs. The term $\frac{w n}{\beta p_{f} q_{f}}$ is the ratio of cost of inputs in its share of dockside market earnings. If fishermen are not quota-constrained, this share equals unity and no rents accrue to the holder of quota rights. If constrained, a lower constrained-optimal input employment implies that its share of dockside earnings exceeds its costs, and the rents are positive.

Turtle bycatch Bycatch is governed by fishermen's choices as dictated by (2) and (3). The aggregate bycatch is

$$
h_{t}^{e}=\underbrace{\frac{z_{t}}{z_{f}} \frac{E\left[(1-\phi)^{1-\beta}\right]}{E\left[\phi^{1-\beta}\right]}}_{\equiv \tau} q_{f}=\tau q_{f} .
$$

The higher the fish quota, the higher is the quantity of inputs employed, which leads to a higher bycatch of turtles. Bycatch also depends on the mean relative abundance of fish in the water. A higher average $\phi$ implies that the expectation term is lower. A higher average relative abundance of fish naturally leads to a lower bycatch.

Thus, in a fishery with unobservable bycatch and tradable fish quotas, sea-turtle bycatch is directly determined by the aggregate fish quota. In order to restrict sea-turtle encounter/mortality to a desired level, the manager has a single regulatory instrument available, $q_{f}$. The social cost of

\footnotetext{
${ }^{15}$ For completeness, the profit function should be written as

$$
\Pi=E\left(p_{f} \phi^{1-\beta} \cdot z_{f} n^{\beta}+r_{f}^{\prime}\left(q_{f}-\phi^{1-\beta} \cdot z_{f} n^{\beta}\right)\right)-w n-r_{f} q_{f}
$$

where $r_{f}$ and $r_{f}^{\prime}$ denote quota prices in the pre- and post-harvest markets. This essentially yields the arbitrage condition $r_{f}=r_{f}^{\prime}$ and allows profit to be expressed as above.
} 
reducing bycatch mortality in this setting is the foregone net profits from harvesting the target stock.

\subsubsection{Fish harvest and bycatch without trade in quotas}

While fishermen are assumed ex-ante homogeneous, a rationale for trade exists as fishermen's harvest possibilities diverge in the operations stage when stock conditions are realized. Without trade, however, a fisherman can not purchase additional quota to land any harvests that exceed quotas purchased in the planning stage. We refer to Figure 1 again for illustration. Let the fish quota holding of all fishermen be $q_{f}$. Then, all fishermen with harvest realizations $\phi_{\text {Low }}$ will land their maximum possible harvest, whereas a fisherman realizing $\phi_{H i g h}$ will hold excess quota; $q_{f}>z_{f} \phi^{1-\beta} n^{\beta}$. These fishermen are landing-constrained. We next compute equilibrium fish harvest and sea-turtle bycatch when no quota trading occurs in the operations stage.

The operations stage In the absence of operations-stage quota trades, fish harvest (and landings) will follow,

$$
h_{f}=\left\{\begin{array}{ll}
z_{f} \phi^{1-\beta} n^{\beta}, & \text { if } \phi<\bar{\phi} \equiv\left(\frac{q_{f}}{z_{f} n^{\beta}}\right)^{\frac{1}{1-\beta}} . \\
q_{f}, & \text { if } \phi \geq \bar{\phi}
\end{array} .\right.
$$

The planning stage Given operations-stage harvests in (5), the problem at the planning stage is to maximize expected profit:

$$
\pi^{e}=p_{f}\left[\int_{\phi_{\min }}^{\bar{\phi}} z_{f} \phi^{1-\beta} n^{\beta} d G(\phi)+q_{f} \int_{\bar{\phi}}^{\phi_{\max }} d G(\phi)\right]-w n .
$$

The first integrand represents harvests that fall below quota, while the second integrand captures stock realizations where landings are constrained by quota. The optimal input choice equates the marginal input cost with its marginal value product:

$$
\beta p_{f} \int_{\phi_{\min }}^{\bar{\phi}} z_{f} \phi^{1-\beta} n^{\beta-1} d G(\phi)=w .
$$

Comparing necessary conditions (6) and (2) indicates two differences. First, the marginal value of an incremental harvest under quota trade is $\left(p_{f}-r_{f}\right)$ since each unharvested unit can be traded in the quota market at price $r_{f}$, whereas marginal value is $p_{f}$ in the absence of quota trade. Second, a marginal unit of harvest (at its maximum feasible) is useless if $\phi>\bar{\phi}$, since without quota trade the overage cannot be landed. Hence, the expectation under (6) is truncated at $\bar{\phi}$.

Expected fish harvest With non-tradable quotas, aggregate fish harvest falls below the aggregate quota since some quota is unutilized. Expected fish harvest follows from (5): 


$$
h_{f}^{e}=q_{f}(1-G(\bar{\phi}))+\int_{\phi_{\min }}^{\bar{\phi}} z_{f} \phi^{1-\beta} n^{\beta} d G(\phi)<q_{f}
$$

where $n$ is determined from (6). The first term denotes the constrained harvest $q_{f}$ weighted by the probability of being quota constrained. The second term accounts for all harvests that fall below the quota, which also explains the last inequality.

Turtle by-catch For relatively high fish abundance realizations, such that $\phi>\bar{\phi}$, fishermen are quota constrained and harvest below the maximum feasible (e.g., in Figure 2, points below and left of $D$, such as $C$ or $A$ ). In this case, the ex ante input allocation is ex post excessive in the sense that the fish harvest capacity, $z_{f} \phi^{1-\beta} n^{\beta}$ exceeds the quota holding. Without opportunity to acquire additional fish quota, the shadow price of unused input is effectively zero. Under our assumption of no unnecessary turtle bycatch, some turtle avoidance occurs. As fish harvest equals $q_{f}$, the choice of $c$ at the operations stage is trivially determined from

$$
q_{f}=z_{f}(1-a(c)) \phi^{1-\beta} n^{\beta} .
$$

Aggregate bycatch then follows as (see Appendix 7.1):

$$
h_{t}^{e}=z_{t} n^{\beta}\left[\int_{\bar{\phi}}^{\phi_{\max }}(1-c(\phi))(1-\phi)^{1-\beta} d G(\phi)+\int_{\phi_{\min }}^{\bar{\phi}}(1-\phi)^{1-\beta} d G(\phi)\right],
$$

where $c(\phi)$ solves (8). The first bracketed term denotes bycatch with avoidance: these are the fishermen who are quota constrained and can afford to reduce bycatch. The second term captures those unconstrained fishermen who put all their inputs toward harvesting fish. In all the numerical illustrations that follow, we assume $a(c)=\frac{1-\sqrt{1-c^{2}}}{2}$ which in the present case implies $c(\phi)=$ $\sqrt{1-\left(\frac{2 q_{f}}{z_{f} \phi^{1-\beta} n^{\beta}}-1\right)^{2}}$ (see Appendix 7.1).

Recall that sea-turtle bycatch under quota trade equals $z_{t} n^{\beta} E\left[(1-\phi)^{1-\beta}\right]$. Since $c(\phi)$ is positive, the term within square brackets in (9) is less than this amount. If, in addition, $n$ here is lower than its quantity under quota trade (see (2) and (3)), bycatch is lower. Otherwise, whether bycatch is higher or lower with quota trading is ambiguous.

A normative comparison of bycatch under the two environments is complicated by the fact that fish harvest is lower without quota trade. A meaningful comparison therefore requires that aggregate fish harvest and landing be kept the same under the two trading environments. One can then examine whether trade leads to a lower or a higher turtle bycatch. To land the same amount of fish with no quota trade, aggregate (and expected) harvest must be higher as some fishermen harvest below their fish quota and divert inputs to reduce sea-turtle bycatch. Therefore, input employed must be larger. We confirm this insight with a numerical example.

Figure 3 reports the percentage increase in input cost and the percentage reduction in sea-turtle bycatch under no quota trade relative to their values under trade holding fish landings constant across the two scenarios. As evident, bycatch is lower without trade in quotas. As discussed 


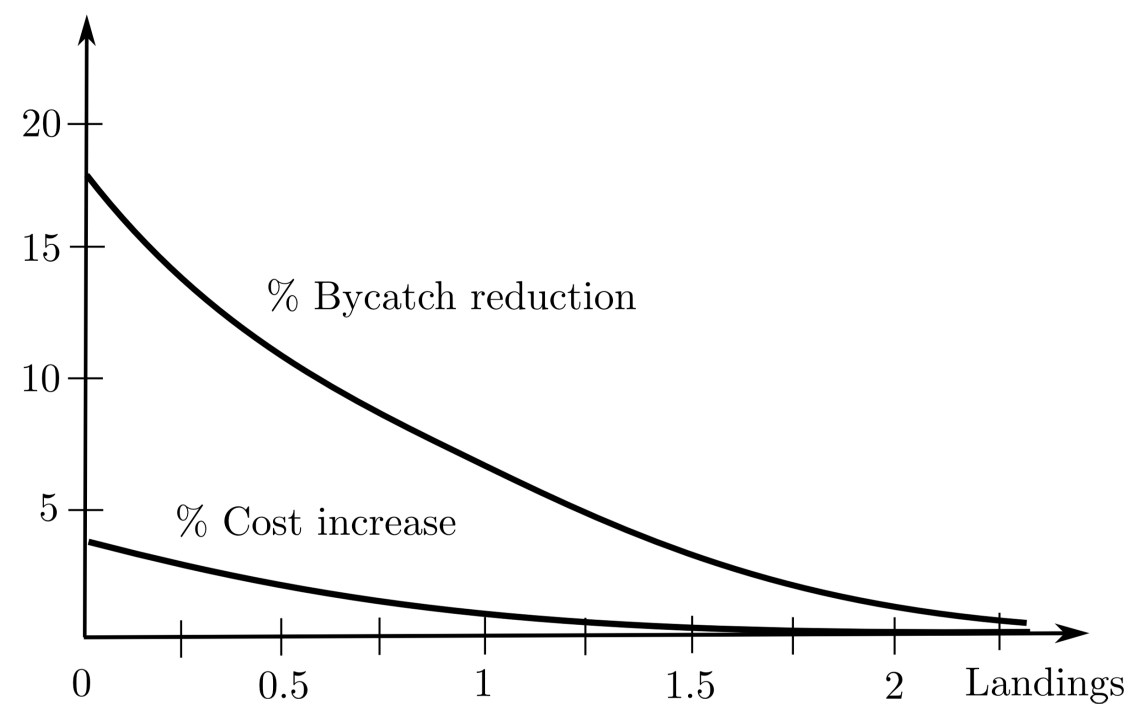

Figure 3: Cost increase and bycatch reduction under no trade scenario. Results assume $\phi$ uniformly distributed on $[0.7,0.9]$ with $w=p_{f}=1, z_{f}=2, z_{t}=0.1, \beta=0.6$ and $q_{f}=1$.

earlier, when quotas cannot be traded, fishermen employ a higher input quantity to obtain the same expected fish landing. As evident, this raises input costs. But then fishermen who encounter high fish abundance cannot direct all inputs to fish harvest as this would exceed their quota. Unutilized inputs are directed to bycatch avoidance and bycatch is lower.

As is also evident, the increase in input cost and the decrease in bycatch diminish as landings increase. The reason is simple. A higher landing target requires a higher quota allocation, which due to diminishing returns implies a lower likelihood of a binding target-species quota constraint. Trade becomes less relevant as the quota allocation moves towards its nonbinding threshold, and the outcomes under two environments converge.

One key lesson drawn by comparing harvest and bycatch under trade vis-à-vis no trade is that under the latter, effort is expended to avoid bycatch, whereas under the former all effort is directed towards harvesting fish. Trade raises the shadow cost of bycatch avoidance. It is then for the manager to evaluate whether cost increases justify bycatch reduction. Prima facie, however, there may be a rationale for restricting trade when bycatch is unobservable.

It is instructive to examine the conditions under which this result will and will not hold. First, as noted above, when the input allocation is higher under the no-trade case and irreversible, the opportunity cost of diverting unutilized $n$ toward bycatch avoidance is zero. Bycatch is lowered due to a good Samaritan effect where, all else equal, fishermen choose to avoid turtles. If quota is tradable, the opportunity cost of diverting $n$ to bycatch avoidance is positive, determined as the productive value of the input in the harvest of fish that can be landed by purchasing additional quota. 
The assumption that the planning-stage input allocation is irreversible is crucial for this result. If, alternatively, unutilized inputs can be costlessly saved for future fishing endeavors, maximization of fishing profits requires $c=0$, and the harvest/bycatch ratio for a fisherman is increasing in the $\phi$

realization, as given by $\left(\frac{1}{\phi}-1\right)^{1-\beta}$. In this case, sea turtle bycatch is unambiguously higher when quota cannot be traded relative to when it can be traded in the operations stage. Without trade, all fishermen harvest their fish quotas. With trade, high (low) $\phi$ fishermen buy (sell) fish quotas and harvest more (less) than $q_{f}$. Since under trade a relatively larger quantity of fish is harvested by high $\phi$ fishermen who incur lower bycatch per unit of target harvest, total bycatch is lower.

\subsection{Quota-based management with at-sea observability}

We now turn to the case where sea-turtle bycatch is monitored at sea. We assume the penalties for violations are sufficiently high and fishermen, as a result, obey their bycatch cap by taking all necessary avoidance measures.

If sea-turtle caps are sufficiently high, they do not bind in equilibrium. The choice problem, as under the unobservable case studied above, is completely guided by fish harvests. On the other hand, if the cap is sufficiently low but fish quotas are sufficiently high, the choice problem is governed primarily by the turtle bycatch cap. Fish harvest management then becomes trivial. Therefore, we focus here on the more interesting case where both fish quotas and bycatch caps bind in the aggregate.

As above, we alternately study scenarios where fish quotas and bycatch permits are and are not traded in the operations stage.

\subsubsection{Fish harvest and bycatch under trade in quotas}

We continue to assume that arbitrage equalizes quota/cap prices across the planning and operations stage since there is no aggregate uncertainty.

The operations stage The fisherman's problem is to maximize profits by balancing fish harvest with turtle bycatch:

$$
\pi(\phi)=\max _{c}\left\{\left(\begin{array}{c}
\left(p_{f}-r_{f}\right) \underbrace{z_{f} \phi^{1-\beta}(1-a(c))}_{h_{f}(\phi)} \\
-r_{t} \underbrace{z_{t}(1-\phi)^{1-\beta}(1-c)}_{h_{t}(\phi)}
\end{array}\right) n^{\beta}-w n+r_{f} q_{f}+r_{t} q_{t}\right\} .
$$

With at-sea observability bycatch must be matched with permit holdings which trade at price $r_{t}$. An optimal and interior choice of $c$, contingent on $\phi$, is then

$$
a^{\prime}(c)=\frac{r_{t}}{p_{f}-r_{f}} \frac{z_{t}}{z_{f}}\left(\frac{1}{\phi}-1\right)^{1-\beta} .
$$


Under our assumption $\phi \in(0,1)$ the term within brackets is finite. Also, for positive harvests to take place, $r_{f}<p_{f}$. Finally, for all $q_{t}>0$, the equilibrium bycatch price $r_{t}<\infty$. Thus, $a^{\prime}(c)$ is finite, and it is positive when $r_{t}>0$.

Recall that $a^{\prime \prime}>0$, which implies that $c$ is increasing in $r_{t}, r_{f}$, and decreasing in $p_{f} .{ }^{16}$ Thus, the higher is the bycatch permit price, the higher is the bycatch avoidance. Conversely, the higher the marginal revenue from fish harvest, the lower is the bycatch avoidance. When $r_{t}>0$, we have $c>0$ for all $\phi<1$. Thus, no fisherman harvests (or lands) his maximum feasible harvest of fish.

Figure 1 illustrates the optimum harvest and bycatch combinations at points $A, B$, and $C$ for $\phi$ realizations of $\phi_{\text {Low }}, \phi_{\text {Med }}$ and $\phi_{\text {High }}$, respectively, when the quota held by all fishermen is at $\left\{q_{f}, q_{t}\right\}$. Equation (11) also indicates that $c$ is decreasing in $\phi$. Thus, a fisherman who encounters a relatively high concentration of fish directs little effort to avoid sea-turtles. The opposite is the case for fishermen who encounter a relatively high concentration of turtles. The above logic also implies that fishermen with relatively higher fish encounters will buy additional fish quotas and sell turtle bycatch permits, while those with lower fish encounters will do the opposite.

The planning stage We have assumed that all quotas are binding; i.e., no quota or bycatch permit goes unutilized. As harvest and bycatch can not exceed their respective limits, it must be the case that

$$
\begin{aligned}
& h_{f}^{e}=q_{f}=n^{\beta} z_{f} E_{\phi}\left\{\phi^{1-\beta}[1-a(\tilde{c}(\phi))]\right\} \\
& h_{t}^{e}=q_{t}=n^{\beta} z_{t} E_{\phi}\left\{(1-\phi)^{1-\beta}(1-\tilde{c}(\phi))\right\},
\end{aligned}
$$

where $\tilde{c}():. \phi \rightarrow(0,1)$ is implicitly defined by $(11)$.

The optimal input choice is obtained by maximizing the expected profit:

$$
\pi^{e}=\underbrace{E_{\phi}\left[\begin{array}{c}
\left(p_{f}-r_{f}\right) z_{f} \phi^{1-\beta}[1-a(\tilde{c}(\phi))] \\
-r_{t} z_{t}(1-\phi)^{1-\beta}(1-\tilde{c}(\phi))
\end{array}\right] \cdot n^{\beta}}_{=\left(p_{f}-r_{f}\right) q_{f}-r_{t} q_{t}}-w n,
$$

which calls for an input quantity that satisfies

$$
w n=\beta\left[\left(p_{f}-r_{f}\right) q_{f}-r_{t} q_{t}\right] .
$$

Input payments (left-hand side) equal their share $(\beta)$ in revenues, as is standard with Cobb-Douglas production functions.

It is worth reiterating that $r_{f}$ and $r_{t}$ are endogenously determined. Thus, equations (12a), (12b), and (13) jointly determine $n, r_{f}$ and $r_{t}$.

\footnotetext{
${ }^{16}$ For example, when $a(c)=\frac{1-\sqrt{1-c^{2}}}{2}$, the above gets

$$
\tilde{c}(\phi)=\sqrt{\frac{1}{1+4\left(\frac{r_{t} z_{t}}{\left(p_{f}-r_{f}\right) z_{f}}\left(\frac{1-\phi}{\phi}\right)^{1-\beta}\right)^{-2}}} .
$$
}


Fish discards and turtle by-catch As evident from (12a), there are no fish discards. Furthermore, turtle bycatch in (12b) is exactly as planned by the manager. Those fishermen who exceed their individual bycatch cap trade from others; in aggregate, sea-turtle bycatch exactly matches the cap $q_{t}$. This result is noteworthy. Recall that bycatch permit sales and purchases determine its equilibrium price at the operations stage. These prices are known in advance (and also prevail) at the planning stage because there is no aggregate uncertainty. These prices in turn determine input employment, which in equilibrium has to be consistent with demand (purchases) and supply (sales) of bycatch permits at the operations stage.

It is worth comparing the costs and benefits with and without at-sea observability. We have shown that trade in fish quotas ensures that fish landing exactly matches its quota, whether bycatch is observable or not. However, when bycatch is unobservable, its quantity is proportional to the fish quota. The manager cannot set fish quotas and turtle caps independently, whereas under observability this will be the case. From (12a) and (12b) we see that the quantity of bycatch per unit of fish harvest will be greater when at-sea behavior is unobserved:

$$
\frac{h_{t}^{e}}{h_{f}^{e}}=\frac{E_{\phi}\left\{(1-\phi)^{1-\beta}(1-\tilde{c}(\phi))\right\}}{E_{\phi}\left\{\phi^{1-\beta}[1-a(\tilde{c}(\phi))]\right\}} \frac{z_{t}}{z_{f}}<\frac{E_{\phi}\left\{(1-\phi)^{1-\beta}\right\}}{E_{\phi}\left\{\phi^{1-\beta}\right\}} \frac{z_{t}}{z_{f}}=\tau,
$$

where $\tau$ is as in (4). A lower observable bycatch requires fishermen to incur avoidance costs, and $\tilde{c}(\phi)>0$ for all $\phi$. The inequality follows from the assumption that $a(c)<c$ for all $c$.

While an observer program can implement a particular bycatch quantity, the cost of landing the same fish quantity without observability is larger by a factor $\left(E_{\phi}\left\{\phi^{1-\beta}\right\} / E_{\phi}\left\{\phi^{1-\beta}[1-a(\tilde{c}(\phi))]\right\}\right)^{\frac{1}{\beta}}$. The cost of deputing observers on boats needs to be accounted for further. The bottom line once again is that bycatch reduction comes at a cost.

\subsubsection{Fish harvest and bycatch without trade in quotas or bycatch permits}

Now suppose that fishermen cannot trade fish quota or bycatch permits and, due to observability, their harvest/bycatch can not exceed their quotas/permits.

The operations stage The quantity of input and ex-post HBPFs will depend on the fish quota and bycatch cap $\left\{q_{f}, q_{t}\right\}$ relative to prices. If the marginal return to the input is high, i.e., $\left\{q_{f}, q_{t}\right\}$ are sufficiently small for given $p / w$, fishermen will have chosen a relatively large $n$ in the planning stage. In this case, quotas and bycatch permits will likely lie in the interior of realized HBPFs. Point $A$ in Figure 4 with quota/permits $\left\{q_{f}, q_{t}\right\}$ represents this case. On the other hand, quota/permit caps are sufficiently large for given $p / w$, the HBPF may fall outside the envelope of zero-avoidance points. This allows for a quota/cap point like $B$ with quota/permits $\left\{q_{f}^{\prime}, q_{t}^{\prime}\right\}$ in Figure 4 .

Below, we present the case where quota/permits are at point like $A$ in Figure 4 . A detailed analysis of equilibrium for points such as $B$ is provided in Appendix 7.7.

As evident, if a fisherman holding $\left\{q_{f}, q_{t}\right\}$ in Figure 4 realizes $\hat{\phi}$, he precisely meets his targets by harvesting at point $A$. If his realized $\phi$ is above say at $\bar{\phi}$, he can meet his fish target and also observe his bycatch cap by catching fewer turtles than $q_{t}$. On the other hand, if his $\phi=\underline{\phi}$, he can 


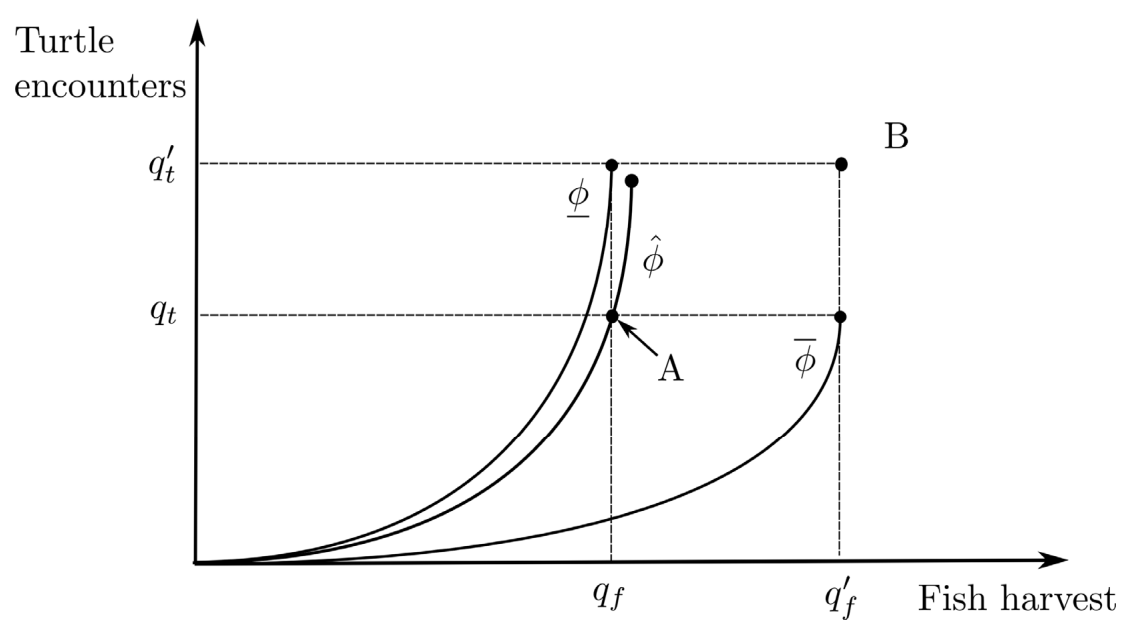

Figure 4: Observable harvests and bycatch under no quota trade.

not fully utilize his fish quota since doing so will violate his bycatch cap. He must sacrifice fish harvest by diverting effort to bycatch avoidance. This argument leads to the following harvesting rules that implicitly determine a fisherman's avoidance efforts, $c$ :

$$
\begin{aligned}
& h_{f}=z_{f}(1-a(c)) \phi^{1-\beta} n^{\beta}=q_{f} \text { for all } \phi \geq \hat{\phi} \\
& h_{t}=z_{t}(1-c)(1-\phi)^{1-\beta} n^{\beta}=q_{t} \text { for all } \phi \leq \hat{\phi} .
\end{aligned}
$$

Thus, while (14a) determines $c$ as a function of $\phi, n$, and $q_{f},(14 \mathrm{~b})$ determines $c$ as a function of $\phi$, $n$, and $q_{t}$. Let these functions be denoted as $\hat{c}_{f}\left(\phi, q_{f}, n\right)$ and $\hat{c}_{t}\left(\phi, q_{t}, n\right)$ respectively. This in turn obtains

$$
\begin{aligned}
& h_{t}=\hat{h}_{t}\left(q_{f}, \phi, n\right) \equiv z_{t}\left(1-\hat{c}_{f}\left(\phi, q_{f}, n\right)\right)(1-\phi)^{1-\beta} n^{\beta}, \quad \phi \geq \hat{\phi} ; \\
& h_{f}=\hat{h}_{f}\left(q_{t}, \phi, n\right) \equiv z_{f}\left(1-a\left(\hat{c}_{t}\left(\phi, q_{t}, n\right)\right)\right) \phi^{1-\beta} n^{\beta}, \quad \phi \leq \hat{\phi} .
\end{aligned}
$$

Thus, (14a) - (15b) completely characterize harvests and bycatches when $\left\{q_{f}, q_{t}\right\}$ is sufficiently tight.

The planning stage Using (15a) and (15b), the expected (and aggregate) fish harvest and sea-turtle bycatch are derived as 


$$
\begin{aligned}
& h_{f}^{e}=q_{f}(1-G(\hat{\phi}))+\int_{\phi_{\min }}^{\hat{\phi}} \hat{h}_{f}\left(q_{t}, \phi, n\right) d G(\phi) ; \\
& h_{t}^{e}=q_{t} G(\hat{\phi})+\int_{\hat{\phi}}^{\phi_{\max }} \hat{h}_{t}\left(q_{f}, \phi, n\right) d G(\phi) .
\end{aligned}
$$

Since quotas/caps can not be traded, the optimal choice of input simply maximizes $p_{f} h_{f}^{e}-w n$, where $h_{f}^{e}$ as expressed by (16a) internalizes the harvest/bycatch quota/cap constraints (see Appendix 7.5):

$$
w=\beta p_{f} \int_{\phi_{\min }}^{\hat{\phi}} z_{f} \underbrace{\left(1-a\left(\hat{c}_{t}\left(\phi, q_{t}, n\right)\right)-\left(1-\hat{c}_{t}\left(\phi, q_{t}, n\right)\right) a^{\prime}\left(\hat{c}_{t}\left(\phi, q_{t}, n\right)\right)\right)}_{<1} \phi^{1-\beta} n^{\beta-1} d G(\phi) .
$$

It is instructive to compare the above with its counterpart under unobservable bycatch, equation (6). Under both cases, landing is observable and fishermen do not harvest more than their fish quotas. Landing is quota-constrained when relative fish abundance exceeds a threshold. Suppose the thresholds turn out to be identical under both cases. Then by (17) inputs employed under observability must be less than that under no observability. This is intuitive: a marginal unit of input not only increases harvest but also by-catch and the latter is costly under observability. This discourages input employment. Expected/aggregate harvest under observability is lower as a result.

Recall that with unobservable at-sea behavior, equilibrium bycatch is lower with no trade vis-à-vis trade, although the reduction comes at a higher cost. Does a similar contrast exist when bycatch is observable? We examine this through a numerical example.

Observable bycatch without quota trade: Without trade in quotas and bycatch caps, the equilibrium is governed by $(14 \mathrm{a})-(17)$. We solve for the equilibrium and contrast costs and bycatch for varying landings targets under the two environments. The results are reported in Figure 5.

Qualitatively, Figure 5 is similar to that exhibited in Figure 3, which reported outcomes with no at-sea observability. Without trade, fishermen employ higher input quantities to land the same quantity of fish, which raises costs. With more inputs and a lower opportunity cost of allocating the inputs to avoidance under no trade, bycatch is smaller. As quotas/landings become larger for given prices, the role of trade diminishes and the differences in outcomes diminishes.

It bears emphasis that under observability and quota/bycatch cap trade, any $\left\{q_{f}, q_{t}\right\}$ chosen by the manager is implementable. This is not possible in the absence of trade. The upshot here is that trade in quotas and caps welfare dominates the absence of trade, when bycatch is observable.

Once again, the result that bycatch is relatively lower without quota trade hinges on the assumption of input irreversibility. In Appendix 7.3, we show that with input reversibility, quota trade instead leads to a lower bycatch. The intuition is similar to as under unobservability. With reversibility, $c=0$ and a fisherman's bycatch/harvest ratio depends on $\left(\frac{1}{\phi}-1\right)^{1-\beta}$. With trade, a relatively higher harvest is reaped by fishermen with high $\phi$ realizations by purchasing additional quotas. 


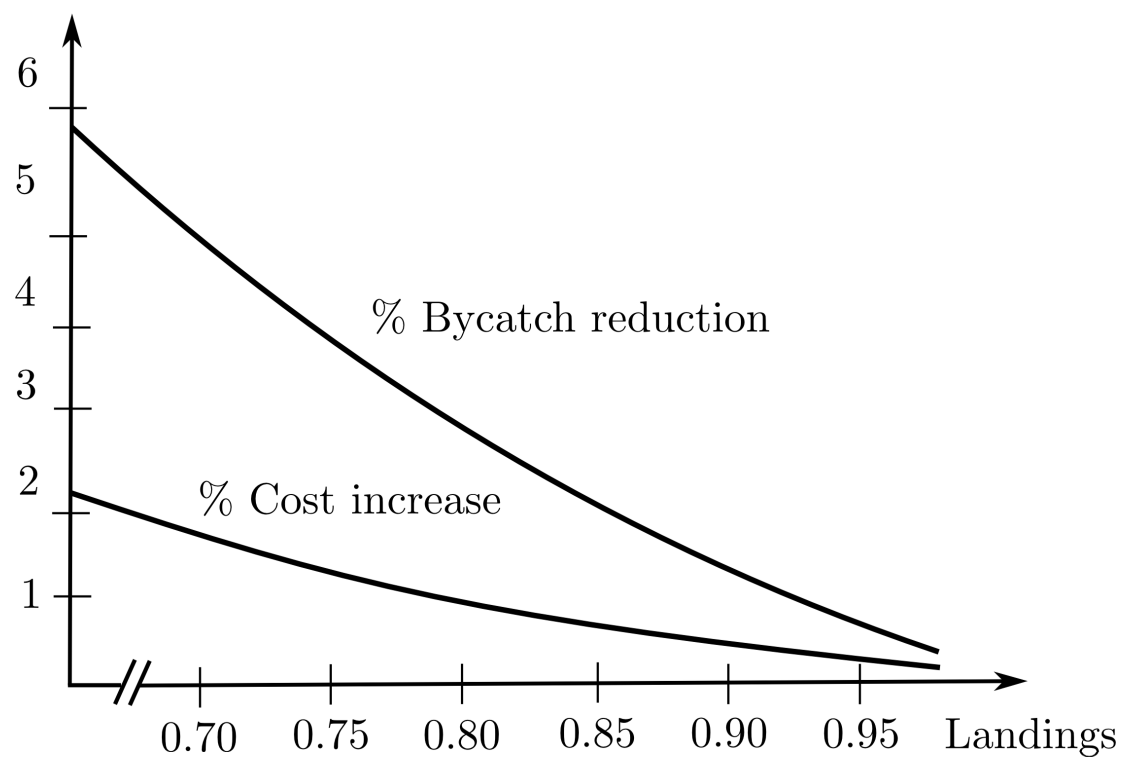

Figure 5: Cost increase and bycatch reduction under no trade scenario, and at-sea observability. Results assume $\phi$ uniformly distributed on $[0.7,0.9]$ with $w=p_{f}=1, z_{f}=2, z_{t}=0.1, \beta=0.6$ and $q_{f}=1$.

Since these fishermen inflict a lower sea-turtle mortality, bycatch/harvest in the aggregate is lower under trade.

\section{Conclusion}

This paper develops a framework to study the design and performance of quota-based management approaches in fisheries experiencing socially harmful bycatch of non-market species. Our model combines endogenous and costly bycatch avoidance, and randomness in harvests of both the target and bycatch stocks. We incorporate our technology within a standard optimizing framework to study fishing behavior and management performance with observable and unobservable at-sea fishing activities, and with and without quota and bycatch permit trades. Empirical evidence from the Gulf of Mexico longline reef fish fishery is presented to motivate our analysis and add context.

Our results suggest that, with trade in fish quotas and bycatch caps, but without at-sea observability, fishermen do not incur the cost of avoiding bycatch while conducting target-stock fishing operations. Trading in bycatch permits is irrelevant. With trade in fish quotas, bycatch can be controlled by the regulator only by reducing the fish quota and foregoing harvest of target fish stock.

Bycatch observability introduces an incentive to undertake costly avoidance efforts, through the introduction of a bycatch permit user cost. A bycatch management scheme with both observability and frictionless quota/cap trading allows fishermen to match aggregate harvests with aggregate 
quota/cap for both the target and bycatch species, at lowest cost. Costs increase when quota/cap is not freely traded. This is because fishermen allocate more inputs to guard against target-stock harvest underages, while at the same time revenue in the fishery is lost without trade as some fish stock quota remains unfished.

Overall, our results hold that efficient target stock/bycatch outcomes emerge under quota/cap management when regulators are able to observe at-sea fishing activity, and if trades of target stock quota and bycatch permits are frictionless. Trading frictions can be overcome with modern communications technology. Achieving at-sea observability at reasonable cost appears possible with recent advances in electronic video monitoring technology. Our assessment of the costs associated with non-quota-based regulation under Amendment 31 suggest tradable bycatch caps should be given serious consideration in the Gulf longline reef fish fishery, and in other fisheries facing smilar bycatch problems.

The costs of non-quota-based bycatch regulations emerge as foregone harvests of valued target stocks and/or higher harvesting costs. These costs can be substantial as evidence suggests in the Gulf of Mexico longline reef fish fishery. If sea-turtle encounters are proportional to longline fishing effort, licence reductions under Amendment 31 appear to address the goal of reducing turtle bycatch. Assuming the $17.6 \%$ encounter rate is accurate and is unaffected by changes in fishing behavior, post Amendment 31, roughly 104 fewer turtle encounters occurred in 2009 (see Table 1). Data limitations do not allow an assessment of the cost of attaining the same turtle bycatch reduction under a tradable bycatch cap program. While empirical evidence suggests Amendment 31 regulations are costly in terms of foregone harvest and increased fishing costs, an important advantage they offer is that at-sea fishing activity need not be monitored. The cost of placing an observer on-board a longline reef fish vessel is estimated at $\$ 1,500$ per day before administrative costs (Perruso, 2012, personal communication). Since quota-based bycatch management would require $100 \%$ observer coverage, the price tag for a longline fleet observer program would exceed $\$ 1.86$ million per year based on the 2008 days at sea.

Recent developments in electronic video monitoring technology on the other hand can provide a viable alternative for implementing $100 \%$ observability (Lara-Lopez et al. 2010). The cost of electronic equipment may be as low as $\$ 30$ per vessel fishing day. Additional costs are incurred to review video footage collected by on-board cameras. These costs could be kept in check through a system of fisherman self-reporting and random auditing (Stanley et al., 2011). That is, fines for miss-reporting bycatch coupled with random audits would likely be sufficient to ensure effective monitoring and thus implementation of a cap-and-trade bycatch management program.

Comparing the costs of restricting bycatch below a particular target under quota- and non-quotabased regulation can be difficult. With sufficient data, a structural model of a target-stock/sea turtle bycatch technology could provide a more complete picture of the cost of reducing bycatch under alternate regulations. Extensions of our model to consider multiple fish and bycatch species and/or multiple production periods could provide additional insights for the design of cap-and-trade bycatch policies. Our paper provides a useful starting point for further investigations. 


\section{References}

Abbott, J. K., Spatial and Strategic Aspects of Fisheries Bycatch, Ph.D. Dissertation, University of California, Davis, 2007.

Abbott, J. K. and J. E. Wilen Regulation of fisheries bycatch with common pool output quotas. Journal of Environmental Economics and Management, 57 (2009):195-204

Arnason, R., On catch discarding in fisheries. Marine Resource Economics, 9 (1994): 189-207.

Bisack, K. D., and J. Sutinen, Harbor porpoise bycatch: ITQs or time/area closure in the New England gillnet Fishery. Land Economics 82 (2006):85-102.

Boyce, J. R., An Economic Analysis of the Fisheries Bycatch Problem. Journal of Environmental Economics and Management 31 (1996): 314-336.

Branch, T. A., and R. Hilborn, Matching catches to quotas in a multispecies trawl fishery: targeting and avoidance behavior under individual transferable quotas. Canadian Journal of Fisheries and Aquatic Sciences, 65 (2008): 1435-1446.

Chakravorty, U., and K. Nemoto, Modeling the effects of area closures and tax policies: a spatial temporal model of the Hawaii longline fishery, Marine Resource Economics, 15 (2000): 179-204.

Curtis, R. and R. L. Hicks, The cost of sea turtle preservation: The case of Hawaii's Pelagic Longliners. American Journal of Agricultural Economics, 82 (2000): 1191-1197.

Fisheries Leadership Sustainability Forum, Bycatch Successes and Challenges Across the Regional Fishery Management Councils. Monterey California, 2009.

Gilman, E. E. Zollett, S. Beverly, H. Nakano, K. Davis, D. Shiode, P. Dalzell and I. Kinan, Reducing sea turtle by-catch in pelagic longline fisheries. Fish and Fisheries, 7 (2006): 2-23.

Holland, D., Markets, pooling and insurance for managing bycatch in fisheries. Ecological Economics, 70 (2010): 121-133.

Hutton, T., O. Thebaud, B. Fulton, S. Pascoe, J. Innes, S. Kulmala and M. Tudman, Use of economic incentives to manage fisheries bycatch: An application to key sectors in Australia's Southern and Eastern Scale fish and Shark Fisheries. CSIRO Marine and Atmospheric Research, August, 2010. 
Huang, H., and P. Leung, Modeling protected species as an undesirable output: The case of sea turtle interactions in Hawaii's longline fishery. Journal of Environmental Management, 84 (2007): $523-33$.

Lara-Lopez, A., J. Davis and B. Stanley, Evaluating the use of onboard cameras in the Shark Gillnet Fishery in South Australia. FRDC Project 2010/049. Australian Fisheries Management Authority 70pp.

Lewison, F., and Crowder, Quantifying the effects of fisheries on threatened species: the impact of pelagic longlines on loggerhead and leatherback sea turtles. Ecology Letters, 7 (2004):221-231.

Mukherjee and Segerson, Turtle Excluder Device Regulation and Shrimp Harvest: The Role of Behavioral and Market Responses. Marine Resource Economics, 26 (2011): 171-189.

National Marine Fisheries Service (NMFS), Estimated Takes of Sea Turtles in the Bottom Longline Portion of the Gulf of Mexico Reef Fish Fishery, July 2006 through December 2008 Based on Observer Data, National Marine Fisheries Service, March 2009.

National Marine Fisheries Service (NMFS), U.S. National Bycatch Report, W. A. Karp, L. L. Desfosse, S. G. Brooke, editors. U.S. Department of Commerce, NOAA Tech. Memo. NMFSF/SPO-117E, 508 p. 2011.

Pascoe, S., J. Innes, D. Holland, M. Fina, O. Thébaud, R. Townsend, J. Sanchirico, R. Arnason, C. Wilcox, and T. Hutton, Use of incentive-based management systems to limit bycatch and discarding. International Review of Environmental and Resource Economics, 4 (2010): 123-161.

Perruso L., and Q. Weninger, Fishing behavior across space, time and depth: With application to the Gulf of Mexico reef fish fishery. Iowa State University, Department of Economics working paper.

Pradhan, N., C., and P. Leung, Sea turtle interactions with Hawaii's longline fishery: An extended multi-objective programming model incorporating spatial and seasonal dimensions. Applied Economics, 40 (2008): 2121-2134.

Segerson, K., Policies to reduce stochastic sea turtle bycatch: An economic efficiency analysis, in Conservation of Pacific Sea Turtles, P. H. Dutton, D. Squires and M. Ahmed, eds. University of Hawai'i Press, 2011, pp. 370-98.

Singh, R., and Q. Weninger, Bio-Economies of scope and the discard problem in multiple-species fisheries. Journal of Environmental Economics and Management, 58 (2009): 72-92.

Singh, R., and Q. Weninger, Trading frictions and fishery discards. Iowa State University, Department of Economics, working paper 12007, April 2012. 
Stanley, R. D., H. McElderry, T. Mawani and J. Koolman, The advantages of an audit over a census approach to the review of video imagery in fishery monitoring. ICES Journal of Marine Science 68 (2011): 1621-1627.

Turner, M. A., Economics without Free-Disposal: The problem of Quota-induced Discarding in Heterogeneous Fisheries. Mimeo, University of Toronto, 1995.

Turner, M. A., Quota-Induced Discarding in Heterogeneous Fisheries. Journal of Environmental Economics and Management 33 (1997): 186-195. 


\section{Appendix to "Cap and trade bycatch management with costly avoidance and stock uncertainty"}

\subsection{Unobservable bycatch without trade in fish quotas}

For all $\phi>\bar{\phi}$, fishermen harvest on points between $D$ and $F$ such as $A$ and $C$ in Figure 2. Then, $\phi$-contingent turtle by-catch realization is given by

$$
h_{t}(\phi)=\left\{\begin{array}{cc}
z_{t}(1-\phi)^{1-\beta} n^{\beta} ; & \phi<\bar{\phi} \\
z_{t}(1-c)(1-\phi)^{1-\beta} n^{\beta} ; & \phi>\bar{\phi}
\end{array}\right.
$$

which leads to (9) in the main text.

Referring back to Figure 2, for points such as $A$ and $C, c>0$. Its value is then determined as the following:

$$
\begin{aligned}
z_{f}(1-a(c)) \phi^{1-\beta} n^{\beta} & =q_{f} \\
\operatorname{Let} a(c) & \equiv \frac{1-\sqrt{1-c^{2}}}{2}=1-\frac{q_{f}}{z_{f} \phi^{1-\beta} n^{\beta}} \\
& \Rightarrow c=\sqrt{1-\left(\frac{2 q_{f}}{z_{f} \phi^{1-\beta} n^{\beta}}-1\right)^{2}}
\end{aligned}
$$

\subsection{Unobservable harvest/bycatch}

With quota trade: It is useful to evaluate first:

$$
\begin{aligned}
E\left(\phi^{1-\beta}\right) & =\frac{1}{2-\beta} \frac{\phi_{\max }^{2-\beta}-\phi_{\min }^{2-\beta}}{\phi_{\max }-\phi_{\min }} ; \\
E\left((1-\phi)^{1-\beta}\right) & =\frac{1}{2-\beta} \frac{\left(1-\phi_{\min }\right)^{2-\beta}-\left(1-\phi_{\min }\right)^{2-\beta}}{\phi_{\max }-\phi_{\min }} ;
\end{aligned}
$$

The bycatch/harvest ratio, $\tau$ as defined in (4) then becomes

$$
\tau=\frac{q_{t}}{q_{f}}=\frac{z_{t}}{z_{f}} \frac{\left(1-\phi_{\min }\right)^{2-\beta}-\left(1-\phi_{\max }\right)^{2-\beta}}{\phi_{\max }^{2-\beta}-\phi_{\min }^{2-\beta}}
$$

Under trade, the input choice and quota price are determined from (2) and (3) as:

$$
n=\left((2-\beta) \frac{\phi_{\max }-\phi_{\min }}{\phi_{\max }^{2-\beta}-\phi_{\min }^{2-\beta}} \frac{q_{f}}{z_{f}}\right)^{\frac{1}{\beta}} ; r_{f}=p_{f}-\frac{w n}{\beta q_{f}}
$$


Under area closure, $\phi \sim U\left[\theta \phi_{\min }+(1-\theta) \phi_{\max }, \phi_{\max }\right]$. Then (30a) yields

$$
n=\left[\frac{2-\beta}{\theta^{1-\beta}} \frac{q_{f}}{z_{f}} \frac{\theta\left(\phi_{\max }-\phi_{\min }\right)}{\phi_{\max }^{2-\beta}-\left(\theta \phi_{\min }+(1-\theta) \phi_{\max }\right)^{2-\beta}}\right]^{\frac{1}{\beta}}
$$

Comparing input employment with and without closure then obtains (31) in the main text.

Without quota trade: Here, it is not possible to get a closed form solution for $n$. However, one can get a non-linear equation to solve for $n$ from (5) and (6) as:

$$
\begin{aligned}
& w=\beta p_{f} \int_{\phi_{\min }}^{\bar{\phi}} z_{f} \phi^{1-\beta} n^{\beta-1} d G(\phi) \Rightarrow n^{\beta-1}=\frac{w}{\beta p_{f} z_{f}}(2-\beta) \frac{\phi_{\max }-\phi_{\min }}{\bar{\phi}^{2-\beta}-\phi_{\min }^{2-\beta}} ; \\
& \bar{\phi} \equiv\left(\frac{q_{f}}{z_{f} n^{\beta}}\right)^{\frac{1}{1-\beta}} \Rightarrow n^{\beta-1}=\frac{w}{\beta p_{f} z_{f}}(2-\beta) \frac{\phi_{\max }-\phi_{\min }}{\left(\frac{q_{f}}{z_{f} n^{\beta}}\right)^{\frac{2-\beta}{1-\beta}}-\phi_{\min }^{2-\beta}}
\end{aligned}
$$

When the aggregate harvest/landing is fixed, $q_{f}$ and $n$ must jointly solve the last expression above and

$$
H^{e}=L=q_{f} \frac{\phi_{\max }-\bar{\phi}}{\phi_{\max }-\phi_{\min }}+\frac{z_{f} n^{\beta}}{2-\beta} \frac{\bar{\phi}^{2-\beta}-\phi_{\min }^{2-\beta}}{\phi_{\max }-\phi_{\min }},
$$

which follows from (7).

\subsubsection{Example 1: Trade versus no-trade when bycatch is unobservable}

Let $\phi$ be uniformly distributed over the support $\left[\phi_{\min }, \phi_{\max }\right]$ with $\phi_{\min }=0.7$ and $\phi_{\max }=0.9$. Let $w=p_{f}=1 ; z_{f}=2, z_{t}=0.1 ; \beta=0.6 ; q_{f}=1$.

Unobservable bycatch, with quota trade: In Appendix 7.2, we show that

$$
n=\left((2-\beta) \frac{\phi_{\max }-\phi_{\min }}{\phi_{\max }^{2-\beta}-\phi_{\min }^{2-\beta}} \frac{q_{f}}{z_{f}}\right)^{\frac{1}{\beta}} ; r_{f}=p_{f}-\frac{w n}{\beta q_{f}} .
$$

With parameters as detailed above, $n=0.366$ and $r_{f}=0.39$. That is, the fish quota price is $39 \%$ of the fish dockside price. Finally, $\tau$ equals 0.0284 ; i.e., turtle bycatch is $2.84 \%$ of the fish harvest.

Unobservable bycatch without quota trade: The derivation of $n$ is presented in 7.2. It is then straightforward to solve for the total fish harvest and turtle bycatch using (7) and (9). For the parameters described above, $n=0.359, h_{f}^{e}=0.981$, and $h_{t}^{e}=0.0276$. That is, the input choice, harvest, and bycatch are all below their values under quota trade. Here, trade in quotas increases the return to inputs which in turn increase harvest and proportional bycatch. 
Instead of keeping quota constant across the two trading environments, for a more meaningful comparison we keep landings fixed. Under quota trade, this is obtained by simply setting $q_{f}$ equal to the desired landing, whereas without quota trade $q_{f}$ and $n$ for any given landing are jointly determined from equations (19) and (20).

\subsubsection{Example 2: Trade versus no-trade when bycatch is observable}

Distributional assumptions and parameter values follow from Example 1.

Observable harvests/bycatch with trade in quotas: We first set the quota/cap thresholds such that they bind in equilibrium. The idea is to restrict sea-turtle bycatch to a level below the equilibrium bycatch when it is unobservable, and then examine how observability impacts input choices and equilibrium outcomes. Fish quotas bind if it falls below

$$
\hat{q}_{f} \equiv\left(\frac{w}{\beta p_{f}}\right)^{\frac{\beta}{\beta-1}}\left[\frac{2-\beta}{z_{f}} \frac{\phi_{\max }-\phi_{\min }}{\phi_{\max }^{2-\beta}-\phi_{\min }^{2-\beta}}\right]^{\frac{1}{\beta-1}} .
$$

To check whether the cap on turtle bycatch binds, one needs to check whether

$$
q_{t}<\tau q_{f},
$$

where $\tau$ is given by (18) as under unobservable behavior. It is easily checked that for $q_{f} \in[0.7,1]$ and $q_{t}=0.01, q_{f}<\hat{q}_{f}$ and $q_{t}<\tau q_{f}$ holds. It is then easily verified that fish quota price falls while sea-turtle cap price rises as $q_{f}$ is raised from 0.7 to $1 .{ }^{17}$ The converse also holds true. That is, keeping fish quota fixed sea-turtle bycatch price declines while fish quota price rises as bycatch cap is raised. The result is as expected because fish harvest and sea-turtle bycatch are output complements.

\subsection{Equilibrium when input is chosen after observing $\phi$, i.e., equilibrium with reversible inputs}

In this alternative set up, it is assumed that every fisherman first gets an i.i.d. draw from $G(\phi)$ and then makes his input choice. The equilibrium is identical to the case when inputs can be returned to the port without any cost. Below we derive equilibrium expressions corresponding to the cases undertaken (irreversible inputs) in the main text of the paper.

\subsubsection{Unobservable bycatch with quota trade}

All fisherman, as before, carry the same quota $q_{f}$ when they head out to sea. ${ }^{18}$ Their $\phi$-contingent profits are

\footnotetext{
${ }^{17}$ See Singh and Weninger (2013) for details.

${ }^{18}$ Of course, they can all directly buy quotas from the management after realizing their $\phi$. The result will be identical.
} 


$$
\Pi=\left(p_{f}-r_{f}\right) \phi^{1-\beta} \cdot z_{f} n^{\beta}-w n+r_{f} q_{f},
$$

An interior choice of $n$ solves

$$
\beta\left(p_{f}-r_{f}\right) \phi^{1-\beta} \cdot z_{f} n^{\beta-1}=w \Rightarrow n=\phi\left(\frac{\beta\left(p_{f}-r_{f}\right) z_{f}}{w}\right)^{\frac{1}{1-\beta}}
$$

Here, $\frac{n}{\phi}$ is constant for everybody, whereas when input is chosen before observing $\phi$ (as in the main text), it is $n$ which is constant for everybody. After aggregating over the unit mass of fishermen, in equilibrium

$$
E\left[\phi^{1-\beta} n^{\beta}\right] \cdot z_{f}=q_{f}
$$

Quota price can be obtained by combining the above with (22): ${ }^{19}$

$$
E(\phi)\left(\frac{\beta\left(p_{f}-r_{f}\right) z_{f}}{w}\right)^{\frac{\beta}{1-\beta}}=\frac{q_{f}}{z_{f}} \Rightarrow r_{f}=p_{f}\left(1-\frac{w}{\beta p_{f} z_{f}} \frac{q_{f}^{\frac{1-\beta}{\beta}}}{\bar{\phi}^{\frac{1-\beta}{\beta}}}\right)
$$

It is useful to compare the above with the expression for quota prices when inputs are chosen before $\phi$ is realized. In the main text, it can be shown that

$$
r_{f}=p_{f}\left(1-\frac{w}{\beta p_{f} z_{f}} \frac{q_{f}^{\frac{1-\beta}{\beta}}}{\left(E\left[\phi^{1-\beta}\right]\right)^{\frac{1}{\beta}}}\right)
$$

Since $E\left[\phi^{1-\beta}\right]<\bar{\phi}^{1-\beta}$ due to Jensen's inequality, $r_{f}$ is lower when fishermen face uncertainty after input employment. It does not come as a surprise. Naturally, if fishermen do not face uncertainty the aggregate outcome is more efficient. Quota rents will be higher.

Turtle bycatch also follows from the choice of $n$ discussed above

$$
h_{t}^{e}=z_{t} E\left[(1-\phi)^{1-\beta} n^{\beta}\right]=z_{t} E\left[(1-\phi)^{1-\beta} \frac{\phi^{\beta}}{\bar{\phi}}\right] \frac{q_{f}}{z_{f}}
$$

instead of

\footnotetext{
${ }^{19}$ Alternatively, combining (25) and (23) gets

$$
r_{f}=p_{f}\left(1-\frac{w E(n)}{\beta p_{f} q_{f}}\right) .
$$

instead of

$$
r_{f}=p_{f}\left(1-\frac{w n}{\beta p_{f} q_{f}}\right) .
$$

as in the main text. Indeed, the interpretation of both equations is identical. Note that, in the latter, $E(n)=n$.
} 


$$
h_{t}^{e}=\frac{z_{t}}{z_{f}} \frac{E\left[(1-\phi)^{1-\beta}\right]}{E\left[\phi^{1-\beta}\right]} \frac{q_{f}}{z_{f}}
$$

For the example 3.1.3, turtle bycatch with $\phi$ - contingent choices give $h_{t}^{e}$ to be $2.82 \%$ instead of $2.84 \%$. Once again, this is solely due to the timing of the resolution of uncertainty w.r.t. the optimal input choice.

\subsubsection{Unobservable bycatch without quota trade}

Here the profit maximization problem equates marginal revenue with the marginal cost, as long as the optimal input choice does not exceed one's quota $q_{f}$ :

$$
\beta p_{f} \phi^{1-\beta} \cdot z_{f} n^{\beta-1}=w \Rightarrow n=\phi\left(\frac{w}{z_{f} \beta p_{f}}\right)^{\frac{1}{\beta-1}}
$$

The value of $\phi$ below which these choices are interior, denoted as $\hat{\phi}$, follows from

$$
\hat{\phi}^{1-\beta} \cdot z_{f} n^{\beta}=\hat{\phi} z_{f}\left(\frac{w}{z_{f} \beta p_{f}}\right)^{\frac{\beta}{\beta-1}}=q_{f}
$$

Thus, $\phi$-contingent fish harvests are:

$$
h_{f}=\left\{\begin{array}{ll}
z_{f} \phi\left(\frac{w}{z_{f} \beta p_{f}}\right)^{\frac{\beta}{\beta-1}}, & \text { if } \phi<\hat{\phi} \equiv \frac{q_{f}}{z_{f}}\left(\frac{w}{z_{f} \beta p_{f}}\right)^{\frac{\beta}{1-\beta}} . \\
q_{f}, & \text { if } \phi \geq \hat{\phi}
\end{array} .\right.
$$

Obtaining aggregate fish harvest as well as sea-turtle bycatch is then straightforward.

$$
\begin{aligned}
& h_{f}^{e}=z_{f}\left(\frac{w}{z_{f} \beta p_{f}}\right)^{\frac{\beta}{\beta-1}} \int_{\phi_{\min }}^{\hat{\phi}} \phi d G(\phi)+(1-G[\hat{\phi}]) q_{f} \\
& h_{t}^{e}=\frac{z_{t}}{z_{f}} q_{f}\left[\int_{\phi_{\min }}^{\hat{\phi}}\left(\frac{1-\phi}{\phi}\right)^{1-\beta} \frac{\phi}{\hat{\phi}} d G(\phi)+\int_{\hat{\phi}}^{\phi_{\max }}\left(\frac{1-\phi}{\phi}\right)^{1-\beta} d G(\phi)\right]
\end{aligned}
$$

When input is chosen before observing $\phi$, uncertainty-whether the quota will bind or not-depresses input employment. Overall fish harvest as a result lies below the outstanding quota. When fishermen choose inputs after observing $\phi$, only those with sufficiently low $\phi$ harvest below the quota. Overall, fish harvest is higher. In this context, it is useful to revisit Example 3.1.3 discussed in the text. For the selected parameters, $\hat{\phi}=0.38$. Since $\phi_{\min }=0.7>\hat{\phi}$, all fishermen are individually quota constrained; their choices are solely determined by their quota. As a result, the harvest, individually as well as in the aggregate, exactly matches the outstanding quota.

Moreover, when inputs are chosen before observing $\phi$, those with high $\phi$ harvest fish below their maximum harvestable fish (because they can not take it to the port) and instead expend resources to lower sea-turtle mortality. This margin is absent under input employment after observing $\phi$. Thus, sea-turtle mortality is higher under the specification referee prefers. For Example 3.1.3 discussed 
above, sea-turtle mortality is $2.76 \%$ of fish harvest in the paper. With the above specification, it turns out to be $2.85 \%$.

Finally, $\hat{\phi}<\phi_{\min }$, each fisherman will utilize $n$ depending on their $\phi$ realization, given by

$$
q_{f}=z_{f} \phi^{1-\beta} n_{\phi}^{\beta}
$$

Thus,

$$
n_{\phi}=\left(\frac{q_{f}}{z_{f} \phi^{1-\beta}}\right)^{\frac{1}{\beta}}
$$

Turtle killings for each $\phi$ will be

$$
h_{t \phi}=z_{t}(1-\phi)^{1-\beta}\left(\frac{q_{f}}{z_{f} \phi^{1-\beta}}\right)
$$

Aggregate turtle bycatch is

$$
h_{t}=\frac{z_{t}}{z_{f}} q_{f} E \frac{(1-\phi)^{1-\beta}}{\phi^{1-\beta}}=\frac{z_{t}}{z_{f}} q_{f} E \frac{\phi^{\beta}(1-\phi)^{1-\beta}}{\phi}
$$

Thus, whether for turtle bycatch to be lower under trade requires:

$$
E \frac{\phi^{\beta}(1-\phi)^{1-\beta}}{\phi}>E\left(\frac{\phi^{\beta}(1-\phi)^{\beta}}{\bar{\phi}}\right) .
$$

Note that

$$
\begin{aligned}
E \frac{\phi^{\beta}(1-\phi)^{1-\beta}}{\phi} & =E\left[\phi^{\beta}(1-\phi)^{1-\beta}\right] E\left[\frac{1}{\phi}\right] \\
& +\operatorname{Cov}\left[\phi^{\beta}(1-\phi)^{1-\beta}, \frac{1}{\phi}\right] \\
& >E\left(\frac{\phi^{\beta}(1-\phi)^{\beta}}{\bar{\phi}}\right) \\
& +\operatorname{Cov}\left[(1-\phi)^{1-\beta} \phi^{\beta}, \frac{1}{\phi}\right]
\end{aligned}
$$

where the inequality follows from Jensen's inequality. Thus, turtle bycatch is unambiguously lower under trade if the covariance term is positive. Recall that $\phi \equiv \frac{x_{f}}{x_{f}+x_{t}}$. It is reasonable to assume that $\phi>>\frac{1}{2}$; indeed, the higher it is the more likely is the covariance term positive. It is easily checked that for $\phi \in[0.7,0.9]$ and for all $\beta<0.75,(1-\phi)^{1-\beta} \phi^{\beta}$ is monotonically decreasing in. The covariance term is positive and therefore, with reversible inputs, turtle bycatch is lower under trade - in contrast to the case with irreversible inputs.

\subsubsection{Observability and Trade}

There is no quota/cap violation under observability irrespective of what stand one takes on the timing of the resolution of uncertainty. Harvests and mortalities will just match the quotas and 
caps allocated by the management. The only difference will be in their market prices.

Indeed, working out the equilibrium fish harvest and sea-turtle mortality when $n$ is $\phi$-contingent is relatively straightforward compared to the set up used in the paper. Since $c$ is chosen after observing $\phi$, its choice is still given by ${ }^{20}$

$$
a^{\prime}(\tilde{c})=\frac{r_{t}}{p_{f}-r_{f}} \frac{z_{t}}{z_{f}}\left(\frac{1}{\phi}-1\right)^{1-\beta}
$$

The optimal input choice is obtained by maximizing the expected profit, after observing $\phi$ :

$$
n=\phi\left(\frac{\beta}{w}\left(\begin{array}{c}
\left(p_{f}-r_{f}\right) z_{f}[1-a(\tilde{c}(\phi))] \\
-r_{t} z_{t}\left(\frac{1-\phi}{\phi}\right)^{1-\beta}(1-\tilde{c}(\phi))
\end{array}\right)\right)^{\frac{1}{1-\beta}},
$$

where $\tilde{c}(\phi)$ is obtained from the previous result. Finally, $r_{f}$ and $r_{t}$ are jointly determined from

$$
\begin{aligned}
& h_{f}^{e}=z_{f} E\left[\phi\left(\frac{\beta}{w}\left(\begin{array}{c}
\left(p_{f}-r_{f}\right) z_{f}[1-a(\tilde{c}(\phi))] \\
-r_{t} z_{t}\left(\frac{1-\phi}{\phi}\right)^{1-\beta}(1-\tilde{c}(\phi))
\end{array}\right)\right)^{\frac{\beta}{1-\beta}}\right]=q_{f} \\
& h_{t}^{e}=z_{t} E\left[(1-\phi)^{1-\beta} \phi^{\beta}\left(\frac{\beta}{w}\left(\begin{array}{c}
\left(p_{f}-r_{f}\right) z_{f}[1-a(\tilde{c}(\phi))] \\
-r_{t} z_{t}\left(\frac{1-\phi}{\phi}\right)^{1-\beta}(1-\tilde{c}(\phi))
\end{array}\right)\right)^{\frac{\beta}{1-\beta}}\right]=q_{t}
\end{aligned}
$$

To verify whether our conjecture is correct, let $q_{f}=1$ and $q_{t}=2.8 \%$ of fish harvest, i.e., $q_{t}=$ 0.028. Quota prices under the paper's specification $\left\{r_{f}, r_{t}\right\}=\{0.39,0.14\}$, whereas under the above alternative specification it is $\left\{r_{f}, r_{t}\right\}=\{0.18,11.85\}$ instead.

\subsubsection{Observability without trade}

With observability, quotas and caps can not be violated. In the absence of trade, everyone is then constrained either by their bycatch cap or fish quota. Those with sufficiently high $\phi$ will be constrained by $q_{f}$ while those with sufficiently low $\phi$ will be constrained by $q_{t}$. However, as $n$ is chosen after observing $\phi$, individual optimality commands that $c=a(c)=0$. Clearly, in terms of computing the equilibrium, this problem is much simpler than the one undertaken in the main text. For example, in the context of Figure $5, \hat{\phi}$ can now be trivially computed as

$$
\frac{z_{t}}{z_{f}}\left(\frac{1-\hat{\phi}}{\hat{\phi}}\right)^{1-\beta}=\frac{q_{t}}{q_{f}} \Rightarrow \hat{\phi}=\frac{1}{1+\left(\frac{z_{f}}{z_{t}} \frac{q_{t}}{q_{f}}\right)^{\frac{1}{1-\beta}}}
$$

${ }^{20}$ For example, when $a(c)=\frac{1-\sqrt{1-c^{2}}}{2}$, the above gets

$$
\tilde{c}(\phi)=\sqrt{\frac{1}{1+\frac{1}{4}\left(\frac{r_{t} z_{t}}{\left(p_{f}-r_{f}\right) z_{f}}\left(\frac{1-\phi}{\phi}\right)^{1-\beta}\right)^{-2}}} .
$$


Then, fishermen's choices follow

$$
n=\left\{\begin{array}{c}
\left(\frac{q_{t}}{z_{t}(1-\phi)^{1-\beta}}\right)^{\frac{1}{\beta}}, \text { for all } \phi \leq \hat{\phi} \\
\left(\frac{q_{f}}{z_{f} \phi^{1-\beta}}\right)^{\frac{1}{\beta}}, \text { for all } \phi \geq \hat{\phi}
\end{array}\right.
$$

Aggregate fish harvest and sea-turtle mortality readily follows as

$$
\begin{aligned}
h_{f}^{e} & =\frac{q_{t}}{z_{t}} z_{f} \int_{\phi_{\min }}^{\hat{\phi}}\left(\frac{\phi}{1-\phi}\right)^{1-\beta} d G(\phi)+(1-G(\hat{\phi})) q_{f} ; \\
h_{t}^{e} & =G(\hat{\phi}) q_{t}+\frac{q_{f}}{z_{f}} z_{t} \int_{\hat{\phi}}^{\phi_{\max }}\left(\frac{1-\phi}{\phi}\right)^{1-\beta} d G(\phi)
\end{aligned}
$$

Clearly $h_{f}^{e}<q_{f}$ and $h_{t}^{e}<q_{t}$. To answer whether trade leads to a lower bycatch (in $\%$ of fish harvest), we need to increase $q_{f}$ under no trade such that the aggregate fish harvest equals the quota under trade. Increasing both $q_{f}$ and $q_{t}$ by the same factor does not alter $\hat{\phi}$. Thus, to ensure that $h_{f}^{e}=1$ as under trade we reset $\left\{q_{f}, q_{t}\right\}=\{1.0686,0.02992\}$. The remaining parameters are the same. Then, we get $h_{t}^{e}=0.282$ which is higher than under trade. Recall that aggregate landing under both cases is the same, but under trade fishermen incur avoidance costs, which in the aggregate leads to a lower turtle mortality.

Thus, with reversible inputs, trade reduces turtle bycatch irrespective of whether the bycatch is observable or unobservable.

\subsection{Equilibrium under perfect information with unobservable bycatch and trade in fishing quotas}

Here we assume that the managers, as well as fishermen, have perfect information on locationspecific relative abundances. We further assume that the congestion costs are sufficiently high so that in equilibrium (through coordination or otherwise) fishermen spread their harvesting operations uniformly across various locations. As a result, one can identify an individual fisherman with the specific fishing location and its relative stock abundance $\phi$.

A fisherman heading to location $\phi$ then chooses inputs to maximize

$$
\left(p_{f}-r_{f}\right) \theta^{1-\beta} \phi^{1-\beta} \cdot z_{f} n^{\beta}-w n
$$

where $r_{f}$ is the quota price for fish stock. The first order condition for the optimal choice of $n$ is

$$
\beta\left(p_{f}-r_{f}\right) \theta^{1-\beta} \phi^{1-\beta} \cdot z_{f} n^{\beta-1}=w .
$$

which yields

$$
n(\phi)=\phi \theta\left[\frac{\beta\left(p_{f}-r_{f}\right) z_{f}}{w}\right]^{\frac{1}{1-\beta}}
$$

We continue to assume that the fish quota binds. With trade in quotas no discards occur, and 
therefore aggregate harvest equals outstanding quota:

$$
h_{f}=\theta^{1-\beta} \cdot z_{f} \int_{\phi} \phi^{1-\beta} n(\phi)^{\beta} d G(\phi)=\theta z_{f}\left[\frac{\beta\left(p_{f}-r_{f}\right) z_{f}}{w}\right]^{\frac{\beta}{1-\beta}} E[\phi]=q_{f} .
$$

In $\operatorname{turn}^{21}$

$$
r_{f}=p_{f}-\frac{w}{\beta z_{f}}\left(\frac{q_{f}}{z_{f} \theta E(\phi)}\right)^{\frac{1-\beta}{\beta}}
$$

Clearly, the higher the $q_{f}$, the lower is $r_{f}$. We assume that $q_{f}<z_{f} E(\phi)\left(\frac{\beta z_{f} p_{f}}{w}\right)^{\frac{\beta}{1-\beta}}$, so that $r_{f}>0$ in equilibrium. Turtle bycatch is now given by

$$
\begin{aligned}
h_{t} & =\theta^{1-\beta} z_{t} \int_{\phi}(1-\phi)^{1-\beta} \cdot n(\phi)^{\beta} d G(\phi)= \\
& \theta\left[\frac{\beta\left(p_{f}-r_{f}\right) z_{f}}{w}\right]^{\frac{\beta}{1-\beta}} z_{t} \int_{\phi}(1-\phi)^{1-\beta} \cdot \phi^{\beta} d G(\phi) \\
& =\underbrace{\frac{E\left[(1-\phi)^{1-\beta} \cdot \phi^{\beta}\right]}{E(\phi)} \frac{z_{t}}{z_{f}}}_{\tau} q_{f}
\end{aligned}
$$

The bycatch ratio is $\frac{E\left[(1-\phi)^{1-\beta}\right]}{E\left(\phi^{1-\beta}\right)} \frac{z_{t}}{z_{f}}$ when $\phi$ is realized only after fishermen reach their fishing locations. As one would expect, with ex-ante perfect information of location-specific relative abundances, discards are also lower because

$$
\frac{E\left[(1-\phi)^{1-\beta} \phi^{\beta}\right]}{E(\phi)}<\frac{E(1-\phi)^{1-\beta} E\left(\phi^{\beta}\right)}{E(\phi)}<\frac{E(1-\phi)^{1-\beta}}{(E(\phi))^{1-\beta}}<\frac{E(1-\phi)^{1-\beta}}{E\left(\phi^{1-\beta}\right)}
$$

Fishery wide harvesting costs are represented by aggregate amount of inputs employed

$$
\int_{\phi} n(\phi) d G(\phi)=E(\phi) \theta\left[\frac{\beta\left(p_{f}-r_{f}\right) z_{f}}{w}\right]^{\frac{1}{1-\beta}}=(\theta E(\phi))^{1-\frac{1}{\beta}}\left(\frac{q_{f}}{z_{f}}\right)^{\frac{1}{\beta}},
$$

where we have used (23) in the last step. A lower $\theta$ truncates the lower tail of the distribution of $\phi$ and $E(\phi)$ is therefore larger. Whether inputs employed increase or decrease with $\theta$ is thus ambiguous from the expression.

\footnotetext{
${ }^{21}$ Notice here that for each fisherman $r_{f}=p_{f}-\frac{w n}{\beta h_{f}}$ holds, whereas for the case dealt in the main text $r_{f}=p_{f}-\frac{w n}{\beta q_{f}}$ holds. The latter no longer holds now.
} 


\subsection{Input choice under observability and no quota/cap trade when $\left\{q_{f}, q_{t}\right\}$ is sufficiently tight}

Using (16a) and (15b), the first order condition for maximizing $p_{f} h^{e}$ w.r.t $n$ is

$$
\begin{aligned}
\frac{w}{p_{f}} & =\beta \int_{\phi_{\min }}^{\hat{\phi}} z_{f}\left(1-a\left(\hat{c}_{t}\left(\phi, q_{t}, n\right)\right)\right) \phi^{1-\beta} n^{\beta-1} d G(\phi) \\
& -\int_{\phi_{\min }}^{\hat{\phi}} z_{f} a^{\prime}\left(\hat{c}_{t}\left(\phi, q_{t}, n\right)\right) \frac{\partial \hat{c}_{t}\left(\phi, q_{t}, n\right)}{\partial n} \phi^{1-\beta} n^{\beta} d G(\phi) .
\end{aligned}
$$

Using (14b), we obtain

$$
\frac{\partial \hat{c}_{t}\left(\phi, q_{t}, n\right)}{\partial n}=\beta \frac{(1-c) n^{\beta-1}}{n^{\beta}}
$$

which together with the previous expression obtains (17) in the main text.

\subsection{Conditions for quotas/caps to bind under observability}

To identify set of $\left\{q_{f}, q_{t}\right\}$ that bind under observability, one has to first consider the case in which there is no cap on turtle bycatch. Then, with trade, all fishermen harvest at their maximum fish harvest point, i.e.,

$$
h_{f}=z_{f} \phi^{1-\beta} n^{\beta} ; h_{f}^{e}=z_{f} n^{\beta} \frac{1}{2-\beta} \frac{\phi_{\max }^{2-\beta}-\phi_{\min }^{2-\beta}}{\phi_{\max }-\phi_{\min }}=q_{f} .
$$

The input required for this to happen is given, in turn, as

$$
n=\left[(2-\beta) \frac{q_{f}}{z_{f}} \frac{\phi_{\max }-\phi_{\min }}{\phi_{\max }^{2-\beta}-\phi_{\min }^{2-\beta}}\right]^{\frac{1}{\beta}}
$$

As long as the quota binds, i.e., $r_{f}>0$. The value of $r_{f}$ is obtained from

$$
\beta\left(p_{f}-r_{f}\right) z_{f} n^{\beta-1} \frac{1}{2-\beta} \frac{\phi_{\max }^{2-\beta}-\phi_{\min }^{2-\beta}}{\phi_{\max }-\phi_{\min }}=w ;
$$

after using the value of $n$ given by (25). There is a value of $q_{f}=\hat{q}_{f}$ such that $r_{f}=0$. This implies that

$$
\beta z_{f} n^{\beta} \frac{1}{2-\beta} \frac{\phi_{\max }^{2-\beta}-\phi_{\min }^{2-\beta}}{\phi_{\max }-\phi_{\min }}=\frac{w n}{p_{f}}
$$


Combining (24), (25) and (26) obtains

$$
\beta \hat{q}_{f}=\frac{w}{p_{f}}\left[(2-\beta) \frac{\hat{q}_{f}}{z_{f}} \frac{\phi_{\max }-\phi_{\min }}{\phi_{\max }^{2-\beta}-\phi_{\min }^{2-\beta}}\right]^{\frac{1}{\beta}},
$$

which gets equation (21) in the main text.

\subsection{Equilibrium under observability and no quota trade when $\left\{q_{f}, q_{t}\right\}$ falls out- side the feasible harvest envelope}

Consider a quota/cap $\left\{q_{f}, q_{t}\right\}=\left\{q_{f}^{\prime}, q_{t}^{\prime}\right\}$ in Figure 5. Let two possible HBPF realizations corresponding to $\phi$ and $\bar{\phi}$ (with $\bar{\phi}>\phi$ ) be as shown in Figure 5. Then $\bar{\phi}$ is as defined in (5) with $q_{f}$ replaced by $q_{f}^{\prime}$. Then, for all $\phi>\bar{\phi}$ the fisherman's maximum feasible fish harvest exceeds his quota $q_{f}^{\prime}$. Now, let $\underline{\phi} \equiv 1-\left(\frac{q_{t}^{\prime}}{z_{t} n^{\beta}}\right)^{\frac{1}{1-\beta}}$ as shown in Figure 5. Those fishermen for whom $\phi>\underline{\phi}$ have their sea-turtle caps $q_{t}>z_{t}(1-\phi)^{1-\beta} n^{\beta}$. Conversely, for all $\phi<\phi$, the maximum fish harvest points on the HBPF will violate the turtle bycatch cap.

Thus, for points such as $B$ with $\left\{q_{f}, q_{t}\right\}$ that lie outside the envelope of maximum harvest points, notice that $\bar{\phi}>\phi$. This implies ${ }^{22}$

$$
\left(\frac{q_{f}}{z_{f}}\right)^{\frac{1}{1-\beta}}+\left(\frac{q_{t}}{z_{t}}\right)^{\frac{1}{1-\beta}}>n^{\frac{\beta}{1-\beta}}
$$

The operations stage Then, as in (5):

$$
h_{f}(\phi)=\left\{\begin{array}{cc}
z_{f} \phi^{1-\beta} n^{\beta}, & \text { if } \phi \in[\phi, \bar{\phi}] \\
q_{f}, & \text { if } \phi>\bar{\phi} .
\end{array}\right.
$$

On the other hand, for those with $\phi<\phi, q_{t}<z_{t}(1-\phi)^{1-\beta} n^{\beta}$. These fishermen can not land their maximum fish harvest as they have to honor their bycatch cap: $h_{t}=q_{t}$. Their fish harvest for all $\phi<\phi$ is given by $\hat{h}_{f}\left(q_{t}, \phi, n\right)$ from (15b). On the other hand, when $\phi>\bar{\phi}, h_{f}=q_{f}$ and turtle bycatch is given by $\hat{h}_{t}\left(q_{f}, \phi, n\right)$ as in $(15 \mathrm{a})$. Thus,

$$
h_{t}(\phi)=\left\{\begin{array}{c}
q_{t} ; \phi<\phi \\
z_{t}(1-\phi)^{1-\beta} n^{\beta} ; \quad \underline{\phi} \leq \phi \leq \bar{\phi} \\
\hat{h}_{t}\left(q_{f}, \phi, n\right) ; \quad \phi>\bar{\phi}
\end{array}\right.
$$

\footnotetext{
${ }^{22}$ However, one needs to keep in mind that $n$ is endogenously determined. Thus the condition above can only be checked after the equilibrium has been computed. If this condition is violated after computing the equilibrium, then equilibrium under $\bar{\phi}<\phi$ will have to be examined.
} 
The planning stage Using (27), the expected fish harvest is given as

$$
h_{f}^{e}=q_{f}(1-G(\bar{\phi}))+\int_{\underline{\phi}}^{\bar{\phi}} z_{f} \phi^{1-\beta} n^{\beta} d G(\phi)+\int_{\phi_{\min }}^{\underline{\phi}} z_{f} \hat{h}_{f}\left(q_{t}, \phi, n\right) d G(\phi)
$$

The profit maximization problem then determines $n$ as

$$
p_{f}\left[\begin{array}{c}
\beta \int_{\underline{\phi}}^{\bar{\phi}} z_{f} \phi^{1-\beta} n^{\beta-1} d G(\phi)+ \\
\beta \int_{\phi_{\min }}^{\phi} z_{f}\left\{1-a\left(\hat{c}_{t}\left(\phi, q_{t}, n\right)\right)-\left(1-\hat{c}_{t}\left(\phi, q_{t}, n\right)\right) a^{\prime}\left(\hat{c}_{t}\left(\phi, q_{t}, n\right)\right)\right\} \phi^{1-\beta} n^{\beta-1} d G(\phi)
\end{array}\right]=w
$$

This equation has the same interpretation as (17) in the main text.

In the absence of trade, aggregate fish harvest falls below the quota. The expected turtle bycatch, using (28), is given by

$$
h_{t}^{e}=q_{t} G(\underline{\phi})+\int_{\underline{\phi}}^{\bar{\phi}} z_{t}(1-\phi)^{1-\beta} n^{\beta} d G(\phi)+\int_{\bar{\phi}}^{\phi_{\max }} \hat{h}_{t}\left(q_{f}, \phi, n\right) d G(\phi)
$$

\subsection{Crew shares and fixed operating expenses}

Table A1: Crew share model

\begin{tabular}{llll}
\hline \hline & Parm. & Std. Err. & Prob. \\
\hline Constant & -0.693 & 0.104 & 0.000 \\
Own-Op. & -0.719 & 0.018 & 0.000 \\
Crew & 0.149 & 0.036 & 0.000 \\
Length & -0.001 & 0.003 & 0.645 \\
Crew $\times$ Length & -0.003 & 0.001 & 0.000 \\
Longline Gear & -0.270 & 0.024 & 0.000 \\
\hline \hline
\end{tabular}

Table A.1 reports results of a parametric crew share model which takes the following form:

$$
\frac{C P_{t}}{R_{t}}=\frac{1}{1+\exp \left(-z_{t} \gamma\right)}+\varepsilon_{t}
$$

where $C P_{t}$ is the payment to the captain and crew reported in the logbook record on trip $t, R_{t}$ is trip revenue, $z_{t}$ is a vector of control variables, $\gamma$ is an unknown parameter vector and $\varepsilon_{t}$ is a mean zero disturbance. Conditioning variables a constant term, an indicator variable equal to 1 if the vessel skipper is also the owner of the vessel and zero otherwise; crew size; vessel length; crew time vessel length; and an indicator variable set equal to 1 if the trip employs longline gear and zero otherwise. The model is estimated with non-linear least squares regression with 16,376 observations. All parameters except vessel length are statistically significant from zero at conventional levels. The longline gear crew share of revenues tends to be smaller as the productivity of longline gear is larger than on baseline vertical line gear trips.

Logbook records exhibit some inconsistency in the crew payment, e.g., some skippers who are also the owners of the vessel do not report a crew share. The harvest cost estimates reported in Table 2 are derived from fitted crew costs. 
Table A2: Annual cost model

\begin{tabular}{llll}
\hline \hline & Parm. & Std. Err. & Prob. \\
\hline Constant & -3.412 & 0.899 & 0.000 \\
$\ln$ (Length) & 1.796 & 0.233 & 0.000 \\
$\ln$ (Horse Power) & 0.369 & 0.102 & 0.000 \\
Days fished/365 & 0.288 & 0.055 & 0.000 \\
\hline \hline
\end{tabular}

Data on annual operating expenses are from a survey of conducted by the Southeast Fisheries Science Center. Fixed operating expenses include expenditures on tackle, vessel repair and maintenance, boat dockage fees, insurance, office expenses, and other annual expenses. Conditioning variables include the length and horse power of the vessel in natural logarithms and the days at sea the vessel fished as a proportion of total available days in a year. Least squares regression was used to fit 178 observations for the 2005-09 fishing seasons. Parameter estimates, estimated standard errors, and p-values are reported in Table A.2. The model R-squared is 0.40. Annual expenses increase with vessel length, horse power and days fishing during a season. Additional regressions found that gear type and the year of fishing had no affect on fixed annual operating expenses.

\section{Extension: Non-quota-based bycatch management}

This section the implications of non-quota-based bycatch regulations using the model developed in the main text. We consider reductions in fishing effort, spatial or temporal fishery closure policies, and gear modification, which comprise Amendment 31 to the Gulf of Mexico Reef Fish Management Plan.

\subsection{Gear modifications}

Gear modifications can affect the transformation relationships embedded in the multi-product harvest technology. Consider a fishery with a fixed landing target and with a market for trade in fish quotas. There are two cases to examine. First, technical innovation may lead to new gear types which lower bycatch/target stock harvest rates at all effort levels and under all stock conditions. The costs of such innovations include research and development expenditures, and the cost of technology adoption for fishermen. In the context of our model, a superior technology implies a higher $z_{f}$ and a higher $\frac{z_{f}}{z_{t}}$. A higher $z_{f}$ increases fish output and reduces input costs (see (3)); a higher $\frac{z_{f}}{z_{t}}$ reduces bycatch $($ see $(4))$.

A more realistic possibility is that innovation alters the bycatch/target stock transformation relation but at a cost of reduced harvest of the target stock. ${ }^{23}$ In this case, turtle bycatch is lower (again, see (4)), but input costs required to attain a given fish harvest are higher (see (3)). An optimal gear restriction will equate the marginal social benefits of bycatch reduction with the marginal increase in costs incurred by fishermen in the aggregate.

\footnotetext{
${ }^{23}$ For example, turtle excluder devices used on shrimp trawl nets in the Gulf of Mexico shrimp fishery allow sea turtles to escape capture and drowning, but also allow some escapement of the target shrimp species. Estimates of the proportion of the shrimp lost with turtle excluder devices are in the range of $2 \%-7.25 \%$ of the shrimp catch (see Mukherjee and Segerson 2011).
} 


\subsection{Effort reduction}

Amendment 31 reduces the number of longline gear permits in the commercial reef fish fishery. Our analysis shows that when bycatch is unobserved, no effort to avoid bycatch is undertaken, i.e., $c=0$. If fishermen have no opportunity to switch gear types, the effect of a reduction in longline effort would be analogous to a reduction in fish quota in our framework. In practice, reef fish fishermen are able to switch from longline to vertical line gear. We therefore re-examine the effect of longline effort limits on turtle bycatch.

We assume the manager issues longline permits to a fraction $\lambda<1$ of reef fish fishermen. The remaining $1-\lambda$ of the population, if they find it worthwhile, can land their quotas using vertical

line gear. Let $\left\{z_{f}^{l}, z_{t}^{l}\right\}$ denote the productivity parameters for longline gear, and let $\left\{z_{f}^{v}, z_{t}^{v}\right\}$ denote the corresponding parameters for the vertical line gear. We assume $\frac{z_{t}^{l}}{z_{f}^{l}}>\frac{z_{t}^{v}}{z_{f}^{v}}$ and $z_{f}^{l}>z_{f}^{v}$. That is, bycatch as a percentage of fish harvest is lower with the vertical line gear, but it comes at the cost of a reduced productivity in fish harvest.

Let $n^{l}$ and $n^{v}$ denote the quantity of input employed by the two gear types. Optimal choices follow (2), and therefore,

$$
n^{l}=\left(\frac{z_{f}^{l}}{z_{f}^{v}}\right)^{\frac{1}{1-\beta}} n^{v} .
$$

Longline fishermen with a higher fish productivity employ relatively more inputs. Indeed, with both gear types in operation, longline fishermen employ more inputs and catch more fish and turtles on average than when only longline gear is employed in the fishery (see (35) in Appendix 8.4).

When we keep the fish landing target under permit restrictions fixed at the level attained under no restrictions, we are able to show (Appendix 8.4) that aggregate input costs increase by a gross factor,

$$
\left(\lambda+(1-\lambda)\left(\frac{z_{f}^{v}}{z_{f}^{l}}\right)^{\frac{1}{1-\beta}}\right)^{-\frac{1-\beta}{\beta}}>1
$$

because the term inside the bracket is less than unity with $\frac{z_{f}^{v}}{z_{f}^{l}}<1$. Further, a more restrictive permit regime (a lower $\lambda$ ) decreases the term inside the bracket, and, therefore, implies a higher cost of meeting aggregate fish landings target. The lower is $\frac{z_{f}^{v}}{z_{f}^{l}}$, the higher is the cost of landing the aggregate fish quota.

As intended, relative to their level under no gear restrictions, sea-turtle bycatch reduces by a gross factor of (see Appendix 8.4)):

$$
\frac{\lambda+(1-\lambda) \underbrace{\left(\frac{z_{t}^{v}}{z_{f}^{v}} / \frac{z_{t}^{l}}{z_{f}^{l}}\right)}_{<1}\left(^{\frac{z_{f}^{v}}{z_{f}^{l}}}{ }^{\frac{1}{1-\beta}}\right.}{\lambda+(1-\lambda)\left(\frac{z_{f}^{v}}{z_{f}^{l}}\right)^{\frac{1}{1-\beta}}} \leq 1
$$

While the costs increase, a more restrictive permit regime (a lower $\lambda$ ) succeeds in reducing bycatch; notice that for $\lambda=1$, the above factor is unity, while with $\lambda=0$, the above simply reduces to 
$\left(\frac{z_{t}^{v}}{z_{f}^{v}} / \frac{z_{t}^{l}}{z_{f}^{l}}\right)$. For any $\lambda<1$, it is evident that the lower the ratio $\frac{z_{t}^{v}}{z_{f}^{v}}$ vis-à-vis $\frac{z_{t}^{l}}{z_{f}^{l}}$ the lower is bycatch for the same amount of fish landing.

\subsection{Spatial restrictions/closures}

The final regulatory action under Amendment 31 involves a closure of a portion of the fishing ground to longline fishing, This regulation can reduce bycatch if the areas that are closed to fishing have high turtle abundance. If the manager does not have area-specific turtle-abundance information, area closures will merely decrease the productivity of fishermen. To capture the effect of the closure regulation we introduce an additional parameter $\theta \in[0,1]$ which measures the portion of the fishing ground that remains accessible to longline gear. A closure is reflected by $\theta<1$. The closure-policy-modified technology can be written as

$$
\left\{h_{f}, h_{t}\right\}=\theta^{1-\beta}\left\{z_{f}^{l} \phi^{1-\beta}, z_{t}^{l}(1-\phi)^{1-\beta}\right\} n^{\beta},
$$

which makes clear the productivity cost of a closure policy. Closures can only increase costs by decreasing productivity, and if the permissible landing remains the same, bycatch will not be affected at all. This is clearly suboptimal.

If, however, the manager has accurate information of turtle abundant areas and closes them to fishing, the effect of lower productivity is counterbalanced by concentrating harvesting into relatively higher-fish-abundant areas. As a result, average relative fish/turtle encounter rates are raised, thereby increasing average fish harvest per unit of bycatch. We continue to assume that fishermen only know the distribution of relative abundance in the area that remains open; as in the previous analysis, their actual values are realized only at sea. Later, we also examine the case where both manager and fishermen have perfect information about site-specific relative abundance.

Suppose relatively high turtle-abundance fishing areas are closed, leaving any $\theta$ portion of fishery open with the distribution of $\phi$, truncated over $\left[\phi_{\min }^{\prime}, \phi_{\max }\right]$ with $\phi_{\min }^{\prime}>\phi_{\min }$. With these modifications, the analytical results derived in the previous sections continue to hold.

Through a numerical example below, we contrast costs and benefits of area closures in a fishery with trade in the fish quota. ${ }^{24}$

\subsubsection{Example 3}

Let the area kept open by the manager be denoted by $\theta<1$, and assume that the area closure truncates the lower tail of uniformly distributed $\phi$ from $U\left[\phi_{\min }, \phi_{\max }\right]$ to,

$$
U[\underbrace{\theta \phi_{\min }+(1-\theta) \phi_{\max }}_{\equiv \phi_{\min }^{\prime}}, \phi_{\max }] .
$$

\footnotetext{
${ }^{24}$ An extension to the case without trade in fish quotas is straightforward, and the message remains the same. We leave it to the interested reader to work this out.
} 
Thus, $\phi_{\max }-\phi_{\min }^{\prime}=\theta\left(\phi_{\max }-\phi_{\min }\right)$.

Sea-turtle bycatch under area closures With unobservable bycatch, no efforts are made to avoid sea-turtles. Assuming that the fish quota binds, we have

$$
\begin{aligned}
& h_{f}^{e}=q_{f}=\theta^{1-\beta} E\left[\phi^{1-\beta}\right] z_{f} n^{\beta} \\
& h_{t}^{e}=\theta^{1-\beta} E\left[(1-\phi)^{1-\beta}\right] z_{t} n^{\beta}=\frac{E\left[(1-\phi)^{1-\beta}\right]}{E\left[\phi^{1-\beta}\right]} \frac{z_{t}}{z_{f}} q_{f} .
\end{aligned}
$$

Compare (30b) with (4): the expressions are identical. However, under a closure, a truncation of the lower tail of $\phi$ decreases $E\left[(1-\phi)^{1-\beta}\right]$ and increases $E\left[\phi^{1-\beta}\right]$. Therefore, as intended, turtle bycatch is lower. Indeed, the more restrictive the closure (a lower $\theta$ ), the higher is the minimum and the average relative fish abundance, the lower is the turtle bycatch.

Input costs under area closures Bycatch under a closure declines. If input costs required to harvest the fish quota could also be lowered, then a closure is clearly a dominant policy. It is not clear from (30a), however, whether more or less inputs need to be employed to harvest $q_{f}$ under a closure. A closure (i.e., $\theta<1$ ) will entail higher input costs if and only if (see Appendix 7.2):

$$
\frac{\theta^{\beta}}{1-(\theta \mu+(1-\theta))^{2-\beta}}>\frac{1}{1-\mu^{2-\beta}},
$$

where $\mu \equiv \frac{\phi_{\min }}{\phi_{\max }} \cdot{ }^{25}$ Clearly, when $\phi_{\min }=0$, i.e., $\mu=0$, the above fails to hold, and some area closure is optimal. There exists a $\hat{\theta} \in(0,1)$ that solves $\hat{\theta}^{\beta}+(1-\hat{\theta})^{2-\beta}=1$, and for all $\theta<\hat{\theta}$, (31) is satisfied. ${ }^{26}$ Thus, input costs begin to increase when a sufficiently large area is closed. This also implies that the rents accruing on quotas fall since the quota price continues to follow $r_{f}=p_{f}-\frac{w n}{\beta q_{f}}$.

In general, if the relative fish abundance is not too low in any region of the fishery - a more realistic scenario $-\mu$ is sufficiently large, and an area closure will require higher input employment to maintain harvest of a fixed fish quota. For example, even for $\mu=0.2$, i.e., $\phi_{\min }=0.2 \phi_{\max }$ the condition (31) holds for all $\theta<1$.

In examples 1 and 2 , we assumed $\left[\phi_{\min }, \phi_{\max }\right]=[0.7,0.9]$. Then $\mu=0.778$. Input costs are higher for all degrees of area closures. Figure 6 below exhibits the percent increase in input costs and the percent decrease in sea-turtle bycatch as a function of area closures, maintaining a fixed harvest of the target stock.

Not surprisingly, the more restrictive the area closure, the higher the input costs required to land the fish quota. To determine the optimal size of the area closure, a manager has to thus weigh the social benefits of bycatch reduction against an increase in costs incurred privately by fishermen.

\footnotetext{
${ }^{25}$ Note that the above only holds at equality when $\theta=1$, irrespective of the value of $\mu$.

${ }^{26}$ By applying L'Hospital's rule, it is easy to check that the LHS $\rightarrow \infty$ as $\theta \rightarrow 0$.
} 


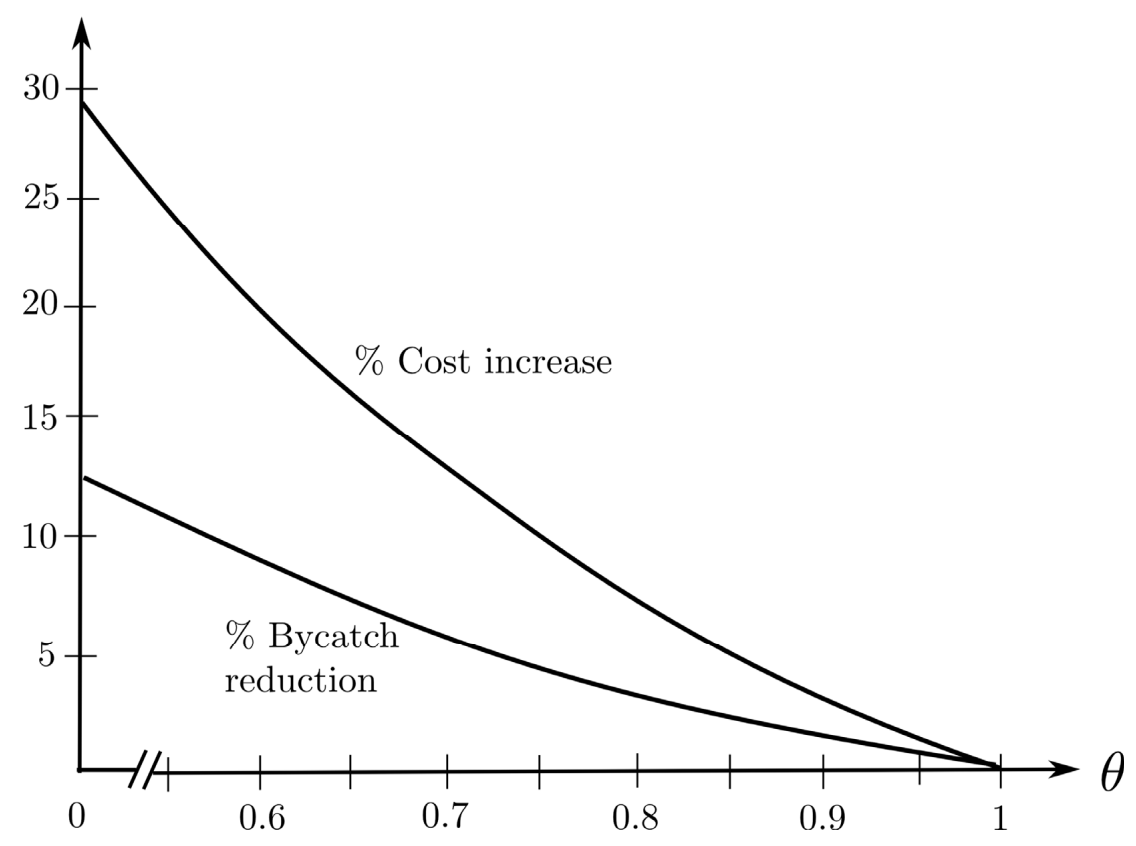

Figure 6: Costs and benefits of area closures when only manager has perfect information

Area closures under perfect information It is worth pointing out that the costs of area closures will increase if managers are not fully informed about the spatial distribution of the bycatch and target stock. Above, we have assumed managers know, in advance, the relative abundance of fish and turtles across regions of the fishery while fishermen do not. How do managers obtain this superior knowledge? Some would argue, on the contrary, that it is the fishermen who are better informed.

To address this asymmetry, below we assume that managers as well as fishermen have perfectly symmetric information about area-specific relative abundance. The details of this case are provided in an Appendix 7.4. Figure 7 below shows the cost-benefit trade-offs for the parameters used in Example 3.

Indeed, with symmetric information, bycatch reduction is lower and input costs are higher, relative to the case with asymmetric information. With perfect information, fishermen are already avoiding areas with high turtle encounters, thus leading to lower reductions under closures. Furthermore, with perfect information, fishermen employ inputs more efficiently, and closures turn out to be costlier.

\subsection{Limits on longline permits}

Gear type specific input choices follow (2):

$$
E\left[\phi^{1-\beta}\right] \cdot z_{f}^{i}\left(n^{i}\right)^{\beta-1}=\frac{w}{\beta\left(p_{f}-r_{f}\right)} ; i=l, v .
$$




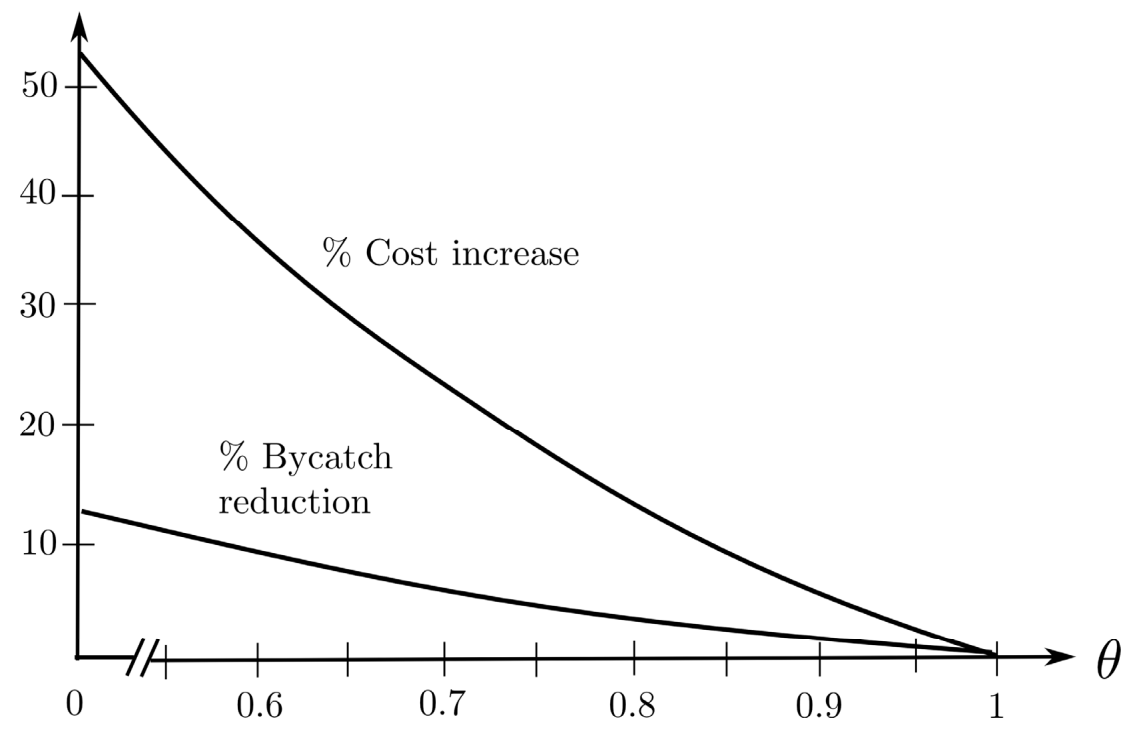

Figure 7: Costs and benefits of area closures under perfect information

which leads to equation (29) in the main text. Quota market clearing requires that

$$
\lambda E\left[\phi^{1-\beta}\right] \cdot z_{f}^{l}\left(n^{l}\right)^{\beta}+(1-\lambda) E\left[\phi^{1-\beta}\right] \cdot z_{f}^{v}\left(n^{v}\right)^{\beta}=q_{f} .
$$

which along with (32) and (29) obtains

$$
\begin{aligned}
q_{f} & =\frac{w}{\beta\left(p_{f}-r_{f}\right)}\left(\lambda n^{l}+(1-\lambda) n^{v}\right) \\
& =\frac{w}{\beta\left(p_{f}-r_{f}\right)} n^{l}\left(\lambda+(1-\lambda)\left(\frac{z_{f}^{v}}{z_{f}^{v}}\right)^{\frac{1}{1-\beta}}\right)
\end{aligned}
$$

Using the above with (32) then yields

$$
n_{l}=\underbrace{\left(\frac{q_{f}}{E\left[\phi^{1-\beta}\right] \cdot z_{f}^{l}}\right)^{\frac{1}{\beta}}}_{\text {input employed when only longline gear is employed }} \underbrace{(\underbrace{\lambda+(1-\lambda)\left(\frac{z_{f}^{v}}{z_{f}^{v}}\right)^{\frac{1}{1-\beta}}}_{<1})}_{>1} ;
$$


Thus, inputs employed by longline gear under permit restrictions increase, and so does per longline fisherman harvest and bycatch. Fishery-wide inputs employed for harvesting $q_{f}$ equals

$$
\begin{aligned}
& \lambda n^{l}+(1-\lambda) n^{v} \\
& =\left(\frac{q_{f}}{E\left[\phi^{1-\beta}\right] \cdot z_{f}^{l}}\right)^{\frac{1}{\beta}} \frac{\lambda+(1-\lambda)\left(\frac{z_{f}^{v}}{z_{f}^{l}}\right)^{\frac{1}{1-\beta}}}{\left(\lambda+(1-\lambda)\left(\frac{z_{f}^{v}}{z_{f}^{l}}\right)^{\frac{1}{1-\beta}}\right)^{\frac{1}{\beta}}} \\
& =\left(\frac{q_{f}}{E\left[\phi^{1-\beta}\right] \cdot z_{f}^{l}}\right)^{\frac{1}{\beta}} \underbrace{\left(\lambda+(1-\lambda)\left(\frac{z_{f}^{v}}{z_{f}^{l}}\right)^{\frac{1}{1-\beta}}\right)^{\frac{\beta-1}{\beta}}}_{>1}
\end{aligned}
$$

Thus aggregate input costs increase under permit restrictions. Indeed, lower the longline permits, i.e., $\lambda$, the higher is the input cost. Finally, aggregate sea-turtle bycatch is given by (using (34) and $(32))$

$$
\begin{aligned}
h_{t}^{e} & =\lambda E\left[(1-\phi)^{1-\beta}\right] \cdot z_{f}^{l}\left(n^{l}\right)^{\beta}+(1-\lambda) E\left[(1-\phi)^{1-\beta}\right] \cdot z_{f}^{v}\left(n^{v}\right)^{\beta} \\
& =\underbrace{q_{f} \frac{E\left[(1-\phi)^{1-\beta}\right]}{E\left[\phi^{1-\beta}\right]} \frac{z_{t}^{l}}{z_{f}^{l}}}_{\text {Bycatch when only longline gear }} \underbrace{[\lambda+(1-\lambda) \underbrace{\left(\frac{z_{t}^{v}}{z_{f}^{v}} / \frac{z_{t}^{l}}{z_{f}^{l}}\right)}_{<1}\left(\frac{z_{f}^{v}}{z_{f}^{l}}\right)^{\frac{1}{1-\beta}}]}_{<1},
\end{aligned}
$$

which, obviously, is lower relative to the case when entire fishery is operated by longline fishermen. 